NATIONAL LABORATORY

\title{
Fuel Flexibility: Landfill Gas Contaminant Mitigation for Power Generation
}

\section{February, 102014}

Prepared by John Storey

Approved for public release:

distribution is unlimited.

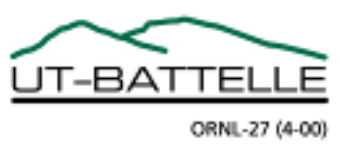




\section{DOCUMENT AVAILABILITY}

Reports produced after January 1, 1996, are generally available free via the U.S. Department of Energy (DOE) Information Bridge.

Web site http://www.osti.gov/bridge

Reports produced before January 1, 1996, may be purchased by members of the public from the following source.

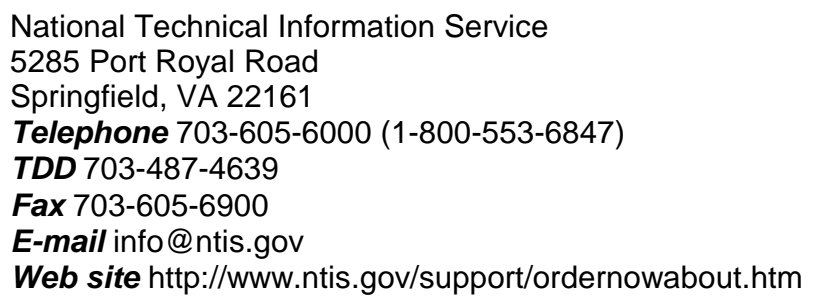

Reports are available to DOE employees, DOE contractors, Energy Technology Data Exchange (ETDE) representatives, and International Nuclear Information System (INIS) representatives from the following source.

Office of Scientific and Technical Information

P.O. Box 62

Oak Ridge, TN 37831

Telephone 865-576-8401

Fax 865-576-5728

E-mail reports@osti.gov

Web site http://www.osti.gov/contact.html

This report was prepared as an account of work sponsored by an agency of the United States Government. Neither the United States Government nor any agency thereof, nor any of their employees, makes any warranty, express or implied, or assumes any legal liability or responsibility for the accuracy, completeness, or usefulness of any information, apparatus, product, or process disclosed, or represents that its use would not infringe privately owned rights. Reference herein to any specific commercial product, process, or service by trade name, trademark, manufacturer, or otherwise, does not necessarily constitute or imply its endorsement, recommendation, or favoring by the United States Government or any agency thereof. The views and opinions of authors expressed herein do not necessarily state or reflect those of the United States Government or any agency thereof. 


\title{
FUEL FLEXIBILITY: CONTAMINANT MITIGATION FOR GAS ENGINES
}

\author{
Authors \\ John Storey \\ Tim Theiss \\ Mike Kass \\ Charles Finney \\ Sam Lewis \\ Brian Kaul \\ Ted Besmann \\ John Thomas \\ Hiram Rogers \\ Michael Sepaniak, Chemistry Department University of Tennessee
}

Date Published: February, 2014

Prepared by

OAK RIDGE NATIONAL LABORATORY

Oak Ridge, Tennessee 37831-6283

managed by

UT-BATTELLE, LLC

for the

U.S. DEPARTMENT OF ENERGY

under contract DE-AC05-00OR22725 



\section{CONTENTS}

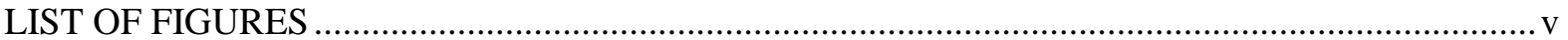

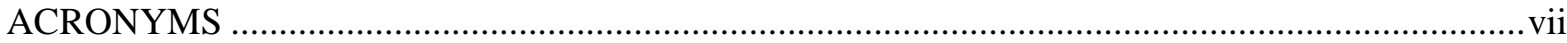

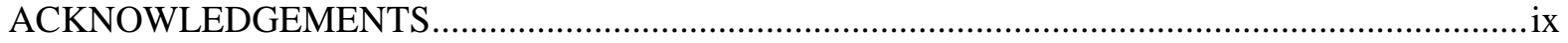

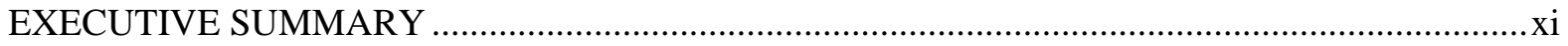

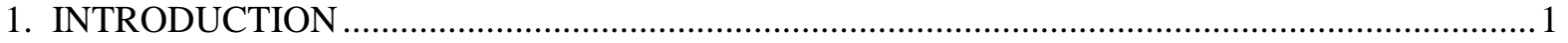

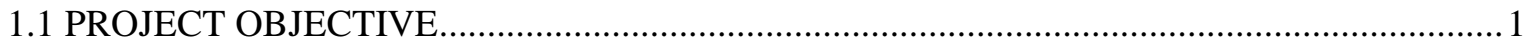

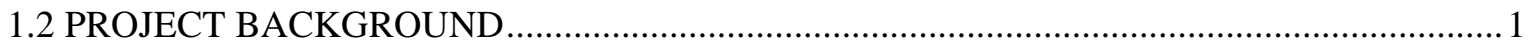

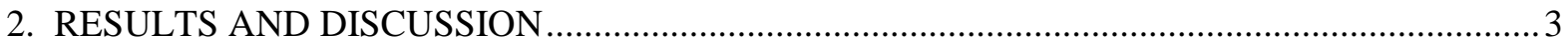

2.1 TASK 1 ELUCIDATION OF THE CHEMISTRY ASSOCIATED WITH SILOXANE IN THE

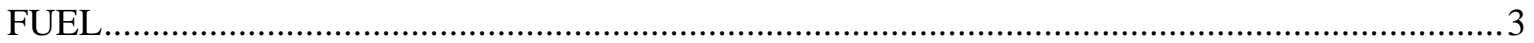

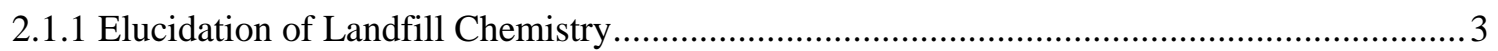

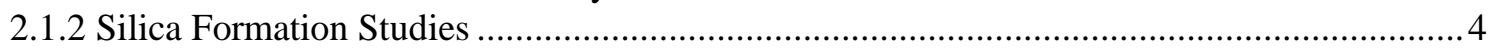

2.2 TASK 2 - DEVELOP AND EVALUATE POTENTIAL SILOXANE MITIGATION

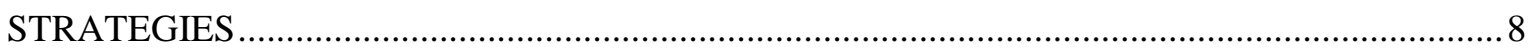

2.2.1 Separation of SiloxanefFrom Landfill Gas Via Jet Separation.......................................... 8

2.2.2 Construction and Evaluation of a Multi-Stage Manifold..................................................... 11

2.2.3 Mitigation of Silica Formation in the Combustion Chamber ............................................ 13

2.3 TASK 3 - DEVELOPMENT OF A SILOXANE SENSOR TO OPTIMIZE MITIGATION

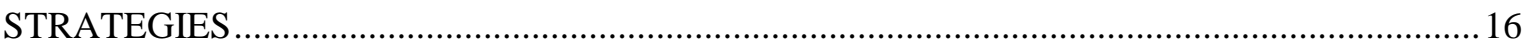

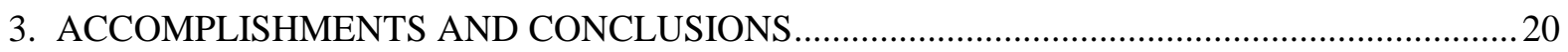

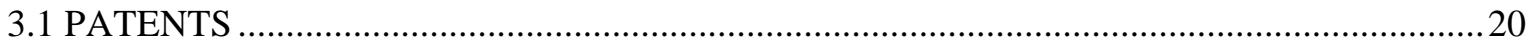

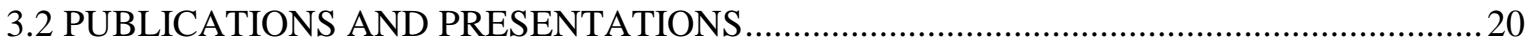

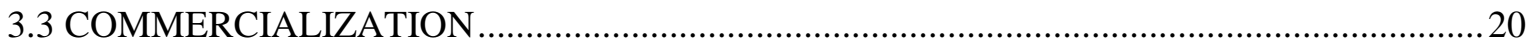

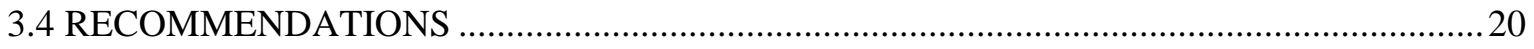

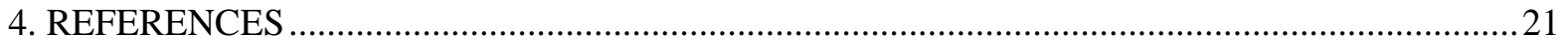

5. LANDFILL SILOXANE GAS SENSING USING DIFFERENTIATING, RESPONSIVE PHASE

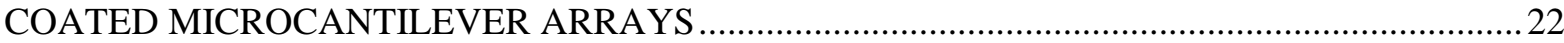





\section{LIST OF FIGURES}

Figure 1. Chromatogram showing excellent separation of siloxanes. ................................................ 3

Figure 2. Piston crown silica deposit from a failed landfill gas engine............................................. 4

Figure 3. X-ray diffraction pattern of a coating on a plug in the exhaust line deposited during the tenhour period in which siloxane was injected into the engine. The very broad peak centered at around $23^{\circ}$ indicates the coating is largely amorphous or glassy.

Figure 4. Secondary electron image of the silica coating on one of the exhaust plugs showing (a) the continuous macroscopic nature of the coating and (b) the microstructure consisting of agglomerated particles.

Figure 5. Results of scratch testing at a variety of loads (g-f or grams-force) showing that the coating

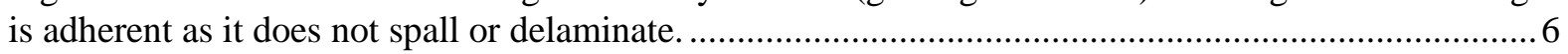
Figure 6. Head from cylinder 1 showing some silica buildup on the exhaust valve and spark plug. ...... 7 Figure 7. Head from cylinder 2 showing silica buildup on the exhaust valve and spark plug. ............... 7 Figure 8. Morphology of silica buildup on exhaust valves showing the difference between cylinders 1 and 2 .......

Figure 9. GC/MS analysis showing siloxane separation (peak area counts in parallel direction) for gas

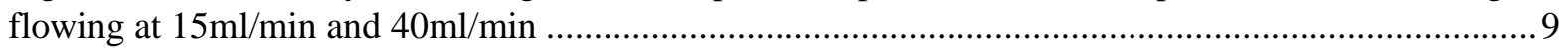
Figure 10. Clean up experiments show that a gap of 0.069 in results in an even distribution of flow, but removal of $75 \%$ of the contaminant. .. 10

Figure 11. Solid model of the lab scale jet separator done in CAD. Drawings per ASME Y14.5 - 1994

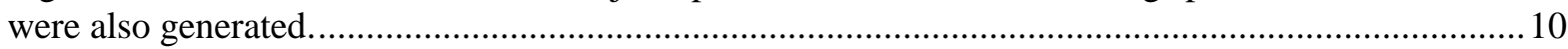

Figure 12. A Jet separator manifold was built to carry out parametric separation effectiveness experiments

Figure 13. Siloxane removal efficiency for single stage separation, as a function of gap length between the nozzle and receiver.

Figure 14. Siloxane removal efficiency for single stage and two stage separation, as a function of gap length between the nozzle and receiver. ........................................................................................ 12

Figure 15. Siloxane removal efficiency as a function of pressure on the "clean" leg of the flow. ....... 13 Figure 16. Results of engine deposit mitigation experiments with the $\mathrm{MgSO}_{4}$ complexing agent. The micrograph of engine deposits showed particle sizes of 1- $10 \mathrm{um}$ in the deposit. X-ray diffraction results (on the right) show a combination of an oxide and $\mathrm{SiO}_{2}$ in the deposits, with no evidence of complex formation.

Figure 17. Spectrophotometer flame containing siloxanes impinging on aluminum substrate. ............ 15

Figure 18. Aluminum substrate disk mounted on cooling plate coated with deposited silica.............. 15

Figure 19. An example of a 4340 steel substrate coated with deposited material with a precursor ratio of Na:Si of $1: 5$ followed by heat treatment at $1000^{\circ} \mathrm{C}$ for $1 \mathrm{~h}$ to fuse the material to the substrate....... 16 Figure 20. Selectivity of the microcantilever array to various types of siloxane compounds at $1 \mathrm{ppm}$ in

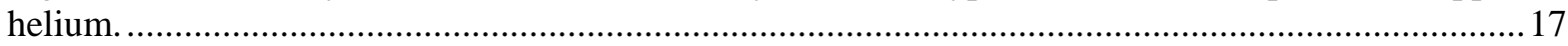

Figure 21. Field-transportable sensor......................................................................................... 18 Figure 22. Field transportable siloxane sensor being tested on a natural gas engine generating siloxane

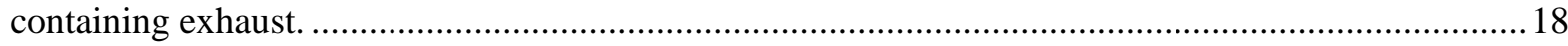

Figure 23. Response of the sensor array to siloxane contaminants in engine intake gas. MC1 - MC8

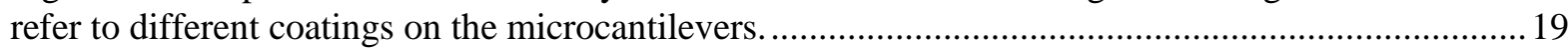

Figure 24. Heated, thermostatically-controlled sensor cell. .............................................................. 19 



\section{ACRONYMS}

$\begin{array}{ll}\text { AFR } & \text { Air Fuel Ratio } \\ \text { AMO } & \text { Advanced Manufacturing Office } \\ \text { ASME } & \text { American Society of Mechanical Engineers } \\ \text { CAD } & \text { Computer Aided Drafting } \\ \text { CFD } & \text { Computational Fluid Dynamics } \\ \text { CHP } & \text { Combined Heat and Power } \\ \text { DMCPS } & \text { Decamethyly Cyclopentasiloxane } \\ \text { DOE } & \text { Department of Energy } \\ \text { EERE } & \text { Office of Energy Efficiency and Renewable Energy } \\ \text { FEERC } & \text { Fuels, Engines, and Emission Research Center } \\ \text { FFF } & \text { Fuel and Feedstock Flexibility } \\ \text { GC-MS } & \text { Gas Chromatography-Mass Spectroscopy } \\ \text { Gpa } & \text { Gigapascal } \\ \text { g-f } & \text { Grams-Force } \\ \text { HMDS } & \text { Hexamethyldisiloxane } \\ \text { HTML } & \text { High Temperature Materials Laboratory } \\ \text { ID } & \text { Inner Diameter } \\ \text { kW } & \text { Kilowatt } \\ \text { lpm } & \text { Liters per minute } \\ \text { MFiX } & \text { Multiphase Flow with Interphase eXchanges } \\ \text { ml } & \text { Milliliter } \\ \text { MW } & \text { Megawatt } \\ \text { MW } & \text { Molecular Weight } \\ \text { OMTS } & \text { Octamethyl Trisiloxane } \\ \text { ORNL } & \text { Oak Ridge National Laboratory } \\ \text { PMDS } & \text { Pentamethyl Disiloxane } \\ \text { ppm } & \text { Parts Per Million } \\ \text { ppmv } & \text { Parts Per Million (volume) } \\ \text { PVC } & \text { Polyvinyl Chloride } \\ \text { SEM } & \text { Scanning Electron Microscopy } \\ \text { TVA } & \text { Tennessee Valley Authority } \\ \text { WED } & \text { Waukesha Engine Dresser } \\ \text { XRD } & \text { X-ray Diffractometry } \\ & \end{array}$




\section{ACKNOWLEDGEMENTS}

This project was funded by the US Department of Energy (DOE), Office of Energy Efficiency and Renewable Energy (EERE) Advanced Manufacturing Office (AMO). This Fuel and Feedstock

Flexibility project was managed as CPS Agreement Number: 17853. The lead organization was the Oak Ridge National Laboratory (ORNL). The project duration was from October 1, 2008 through September 30, 2012.

Other project partners included:

Waukesha Engine Dresser (WED), now GE-Waukesha Engine

Energy Systems Group, Inc.

University of Tennessee 


\section{EXECUTIVE SUMMARY}

Methane, generated by anaerobic decomposition of organic material in landfills or in sewage treatment plants an also known as bio-gas, represents a significant source of renewable energy. Unfortunately, contaminants such as siloxanes, hydrogen sulfide, and chlorinated hydrocarbon gases also accompany the methane in landfill generated gasses. Over time these compounds cause severe damage to the engines and other thermal equipment used to convert the gas to energy, resulting in frequent maintenance and repair. Siloxane is particularly problematic because it leads to solid silica formation within an engine combustion chamber resulting in excessive wear and damage. Siloxanes are organosilicons which originate from personal care products and may also form in the biogas anaerobic digestion process. Siloxanes typically occur at 0.5 to 50 ppmv levels in landfill gas, and up to 200 ppmv in digester gas. Removal of siloxane compounds prior to their ingestion into the engine is currently the most viable means of preventing silica formation and subsequent damage to the engine.

This research project focused on the mitigation of silica damage to engine-based renewable landfill gas energy systems. Characterization of the landfill gas siloxane contamination, combined with characterization of the silica deposits in engines, led to development of two new mitigation strategies. The first involved a novel method for removing the siloxanes and other heavy contaminants from the landfill gas prior to use by the engines. The second strategy sought to interrupt the formation of hard silica deposits in the engine itself, based on inspection of failed landfill gas engine parts. In addition to mitigation, the project had a third task to develop a robust sensor for siloxanes that could be used to control existing and/or future removal processes.

Objective and Tasks. The primary objective of the project was to detect and remove siloxane contaminants from the landfill gas prior to entering the engine fuel system and/or mitigate their harmful impact. The effort was divided into three tasks:

1) Elucidation of the chemistry associated with siloxane in the fuel,

2) Develop and evaluate potential siloxane mitigation strategies, and

3) Development of a siloxane sensor to optimize mitigation strategies.

Results and Conclusions. A new analytical methodology was developed that took advantage of advances in the analysis of gas samples with gas chromatography - mass spectroscopy (GC-MS.) The method was sensitive down to $1 \mathrm{ppm}$, and requires minimal sample handling or sample work up.

The development of mitigation strategies for siloxane contamination in task 2 had mixed success. The first project examined the use of jet separation to remove siloxanes from landfill gas. Jet separation relies on the differences in molecular weight to separate mixtures of gases. It was found ultimately that the combination of high vacuum and high flow required for good separation required excessive electrical power. The second strategy, under open flame conditions, was able to demonstrate the prevention of the formation of hard silica deposits. In the engine, however, it was challenging to entrain the additives into the intake flow, and no change in the deposit hardness was observed. The latter strategy did result in the successful issuance of a patent for the concept.

The third task, the siloxane sensor, resulted in a portable device with the potential for miniaturization into a real-time sensor that could be installed into a landfill gas supply line. Based on microcantilever technology, the siloxane sensor used different chemical coatings to select for different siloxanes as well as for discriminating against other contaminants such as $\mathrm{CO}_{2}$ and water. A publication on the technology was written and is attached at the end of this report. 
The tasks making up this project had several successful outcomes. A new canister sampling and analysis method was developed for siloxane detection in grab samples of landfill gas. An engine demonstration showed that it was possible to reproduce silica deposit formation in a combustion chamber by doping the feed gas with siloxane. Finally, a sensitive and selective sensor system for siloxanes in a landfill gas matrix was demonstrated. It is recommended that future funding for miniaturization of the sensor system be pursued to bring this sensor to commercial viability. Finally, while the two mitigation strategies, the jet separator and the complexation additive, were not fully investigated due to the discontinuation of the research program, both strategies showed some promise. Additional research on these strategies may yield field-ready systems to solve a challenging problem for landfill gas energy systems. 


\section{INTRODUCTION}

\subsection{PROJECT OBJECTIVE}

This project sought to mitigate the silica damage in natural gas engines operating on landfill gas. Silica deposits in engines operating on landfill gas cause failures in the valve train, and, in extreme cases, the piston as well. Silica is formed in the engine by the oxidation of silicon in the engine during combustion of various silicon-containing compounds, such as siloxanes, that are present in the landfill gas. The primary focus of the project was to detect and remove siloxane contaminants from the landfill gas prior to entering the engine fuel system and/or mitigate their harmful impact.

This effort was divided into three tasks:

1) Elucidation of the chemistry associated with siloxane in the fuel,

2) Develop and evaluate potential siloxane mitigation strategies, and

3) Development of a siloxane sensor to optimize mitigation strategies.

\subsection{PROJECT BACKGROUND}

Methane generated by anaerobic decomposition of organic material in landfills and then converted into electricity using engine-generator systems, represents a significant source of renewable energy. In Los Angeles County, for instance, there are several landfill gas projects that produce almost $80 \mathrm{MW}$ of electricity. The engines used in landfill facilities frequently operate with minimal preconditioning of the landfill gas. Unfortunately, contaminants such as siloxanes, hydrogen sulfide, and chlorinated hydrocarbon gases also accompany the methane in landfill generated gasses. Over time these compounds cause severe damage to the engine, resulting in frequent maintenance and repair. Siloxane is particularly problematic because it leads to solid silica formation within the engine combustion chamber resulting in excessive wear and damage. Siloxanes are organosilicons which originate from personal care products and may also form in the landfill gas anaerobic digestion process. Siloxanes typically occur at 0.5 to 50 ppmv levels in landfill gas. Removal of siloxane compounds prior to their ingestion into the engine is currently the most viable means of preventing silica formation and subsequent damage to the engine.

Organochlorine compounds, such as vinyl chloride from the decomposition of polyvinyl chloride (PVC) packaging, are present as well in landfill gas. Combustion of these compounds leads to formation of hydrochloric acid $(\mathrm{HCl})$ in the exhaust gases. $\mathrm{HCl}$ can corrode stainless steel and other powertrain materials. Hydrogen sulfide, $\mathrm{H}_{2} \mathrm{~S}$, results from the digestion of sulfur containing waste such as wallboard. Combustion of $\mathrm{H}_{2} \mathrm{~S}$ results in corrosive exhaust by-products such as sulfuric acid.

The two most common methods for siloxane removal are carbon adsorption and refrigeration, with carbon absorption being the most common option. Activated carbon change out usually occurs every three to six months and the adsorption efficiency is highly dependent on gas chemistry, temperature, and humidity. The carbon adsorption process can be optimized with the incorporation of a siloxane sensor to detect when siloxane breakthrough occurs, thereby signaling activated carbon replacement. Refrigeration is another method used to remove siloxane compounds from landfill gas. However, the removal efficiencies for refrigeration units are low (around 50\%) and require significant amounts of 
energy to operate. As a result, simpler, cheaper, and more efficient siloxane removal methods are desired.

This research project focused on the mitigation of silica damage to engine-based renewable landfill gas energy systems. Characterization of the landfill gas siloxane contamination, combined with characterization of the silica deposits in engines, led to two new mitigation strategies. The first involved a novel method for removing the siloxanes and other contaminants from the landfill gas prior to use by the engines. The second strategy sought to interrupt the formation of hard silica deposits in the engine itself, based on inspection of failed landfill gas engine parts. In addition to mitigation, the project had a third task to develop a robust sensor for siloxanes that could be used to control existing and/or future removal processes. 


\section{RESULTS AND DISCUSSION}

Project results and discussion are organized by the project task.

\subsection{TASK 1 ELUCIDATION OF THE CHEMISTRY ASSOCIATED WITH SILOXANE IN THE FUEL}

\subsubsection{Elucidation of landfill chemistry}

A landfill near Chattanooga, Tennessee was first selected for field studies. The landfill uses a Waukesha engine-generator to generate electricity to sell on the market to the Tennessee Valley Authority (TVA). The landfill uses chillers to condition and pre-treat the landfill gas and was amenable to working with ORNL on field demonstration of these concepts. However, this site became unavailable due to a change in management of the power generation company.

A second site, operated by the Energy Systems Group Inc., was the Iris Glen Landfill in Johnson City, Tennessee, agreed to allow gas sampling. This facility upgrades landfill gas for direct gas pipeline supply as well as using it for steam and power generation for a nearby Veteran's Administration medical complex. Further discussions with Energy Systems Group Inc. led to determination that vinyl chloride, a decomposition product of PVC in landfills, can be used as an indicator of gas cleanup system failure.

The analysis capability for siloxanes and other organic contaminants was upgraded using capital money from the Combined Heat and Power (CHP) program to purchase a new preconcentrator unit and mass spectrometer for the analytical laboratory. Analytical methods for the determination of siloxanes were also implemented with excellent separation of L2 to D6 demonstrated (see Fig. 1). Although no landfill gases were obtained from Iris Glen before the expiration of this project, the results shown in Figure 1 show the promise of this technique for future landfill gas characterization.

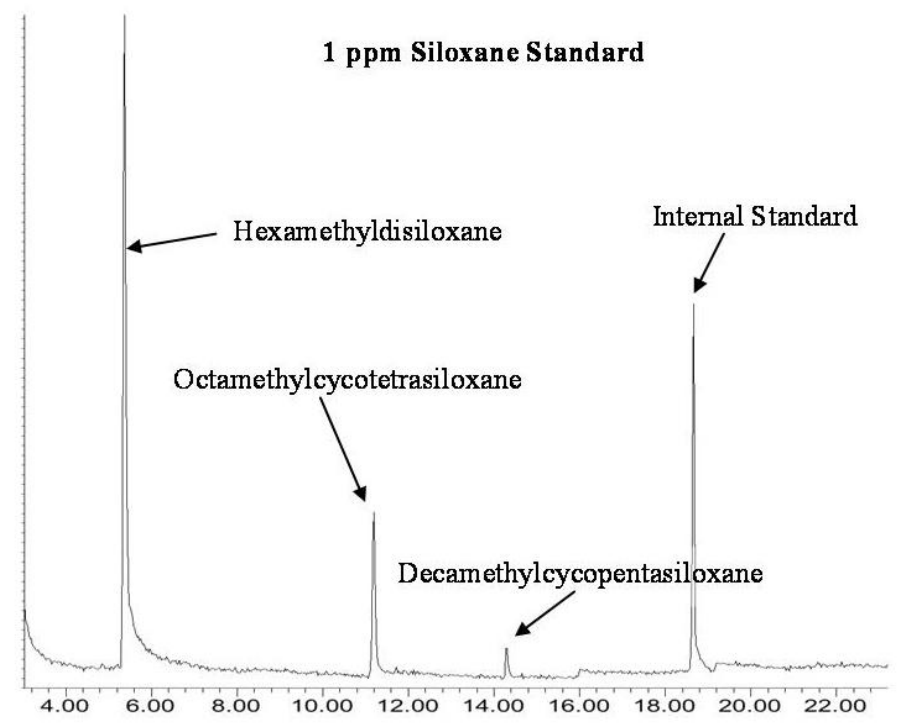

Figure 1. Chromatogram showing excellent separation of siloxanes. 


\subsubsection{Silica Formation Studies}

An ORNL team visited the Waukesha Engine Division (formerly of Dresser Industries, now a division of General Electric) in 2008 to inspect engine parts damaged by operation with landfill gas contaminated with siloxane. Figure 2 shows the top of a piston from a failed engine with large amounts of silica buildup. Samples taken from this part were analyzed at the ORNL High Temperature Materials Laboratory (HTML) and were found to contain both amorphous and crystalline phases of silica. Crystalline phases are caused by slow cooling of the gas phase silica and occurred on the hottest surfaces of the engine such as the piston crown. Amorphous silica (glass) is formed from rapid cooling of the gases, typically near the cylinder walls and on the head of the combustion chamber. Both the crystalline phase and amorphous phase result in failure modes for the engine inc;luding: interference with piston motion and eventual failure, an increase the compression ratio of the engine, and the spalling of large pieces of deposit, also resulting in mechanical failure of valves and other components.

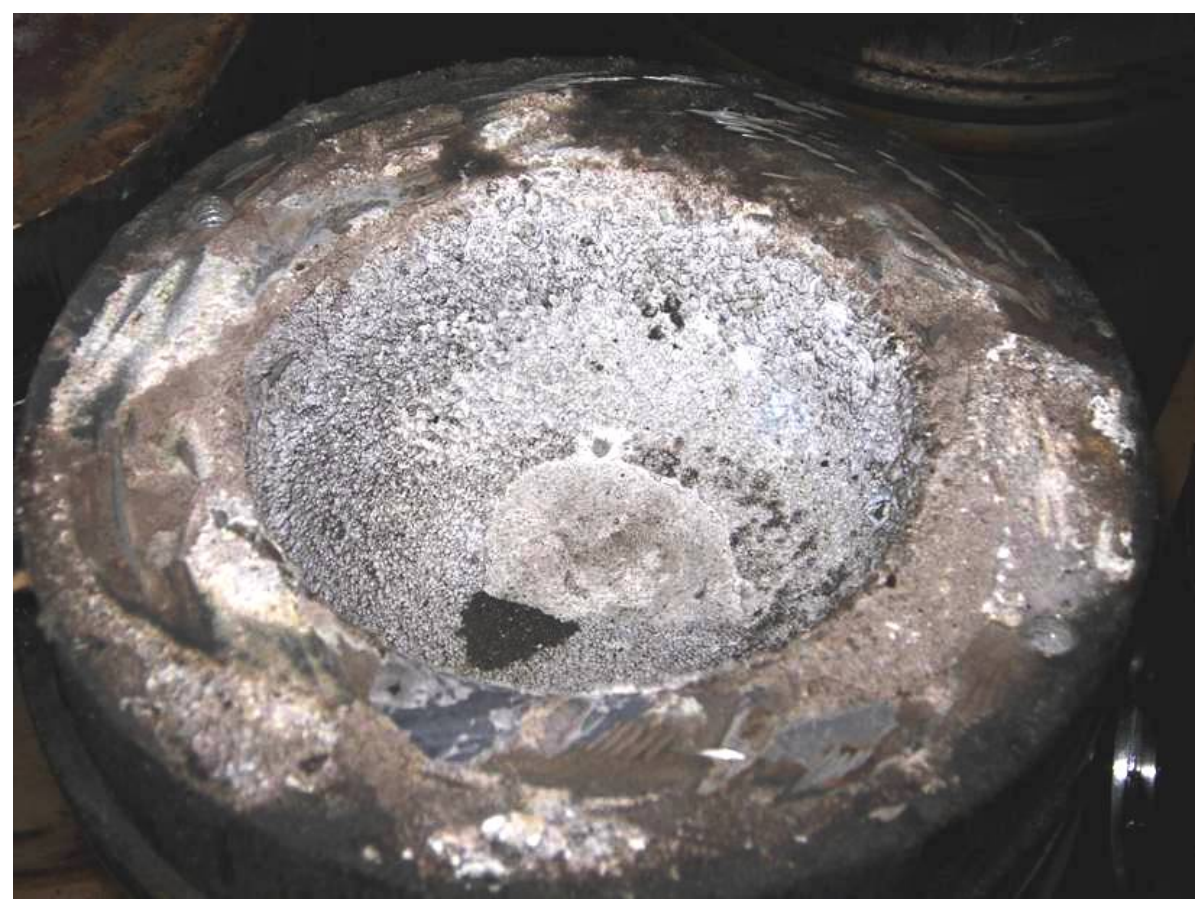

Figure 2. Piston crown silica deposit from a failed landfill gas engine.

In order to study the silica deposition in the laboratory, a small 8.5kW two-cylinder Kohler natural gas engine-generator was obtained and modified for siloxane injection and exhaust temperature measurement. The exhaust section for each cylinder was instrumented for temperature measurement and modified to enable measurement of the air-fuel ratio (AFR). Because small two-cylinder utility engines typically have irregular AFR control, the AFR for cylinders 1 and 2 were 20.6 and 14.5, respectively, at $6 \mathrm{~kW}$ electrical output. Correspondingly, the exhaust gases for cylinder 1 averaged $760^{\circ} \mathrm{C}$ and around $720^{\circ} \mathrm{C}$ for cylinder 2 . The lower temperature for cylinder 2 is the result of richer combustion as evidenced by the lower AFR. In order to monitor silica formation and accumulation, metal coupons were placed in the exhaust ports used to measure AFR and long term exposure commenced.

An initial test was conducted to determine whether the systems would be useful as a testbed for evaluating the effect of silica deposition, decamethylcyclopentasiloxane (D5) was injected into the fuel 
stream at $0.002 \mathrm{ml} / \mathrm{min}$ (39 ppm by volume). Significant buildup occurred quickly (10 hours) with visible material on plugs seated in each of two the engine exhaust lines.

The material deposited on the plugs was analyzed. X-ray diffractometry (XRD) (Fig. 3) revealed that the deposited material was largely amorphous or glassy with a small carbon peak from likely soot deposits and a brass peak, possibly from the plug material. Scanning Auger analysis provided a representative elemental analysis from random points on the coating in Table 1, which show that it is almost entirely silica (high silicon and oxygen content) with very minor amounts of carbon (soot) and zinc (probably from a lubricating oil additive). A secondary electron scattering image seen in Fig. 4 reveals that the coating on the plugs consists of agglomerated material that was particulate produced in combustion.

Table 1. Scanning Auger spectroscopy at several random points on the surface of one of the plug coatings indicate it is largely silica as seen from the silicon and oxygen content with minor amounts of soot and zinc from an oil additive

\begin{tabular}{lllll}
\multicolumn{5}{c}{ Composition (at.\%) } \\
Point & C & O & Si & Zn \\
\hline 1 & 3.4 & 51.0 & 43.6 & 2.0 \\
2 & 1.2 & 51.3 & 46.3 & 1.3 \\
3 & 2.8 & 45.0 & 50.8 & 1.4 \\
4 & 2.4 & 47.9 & 48.4 & 1.3 \\
5 & 2.7 & 48.8 & 47.0 & 1.5
\end{tabular}

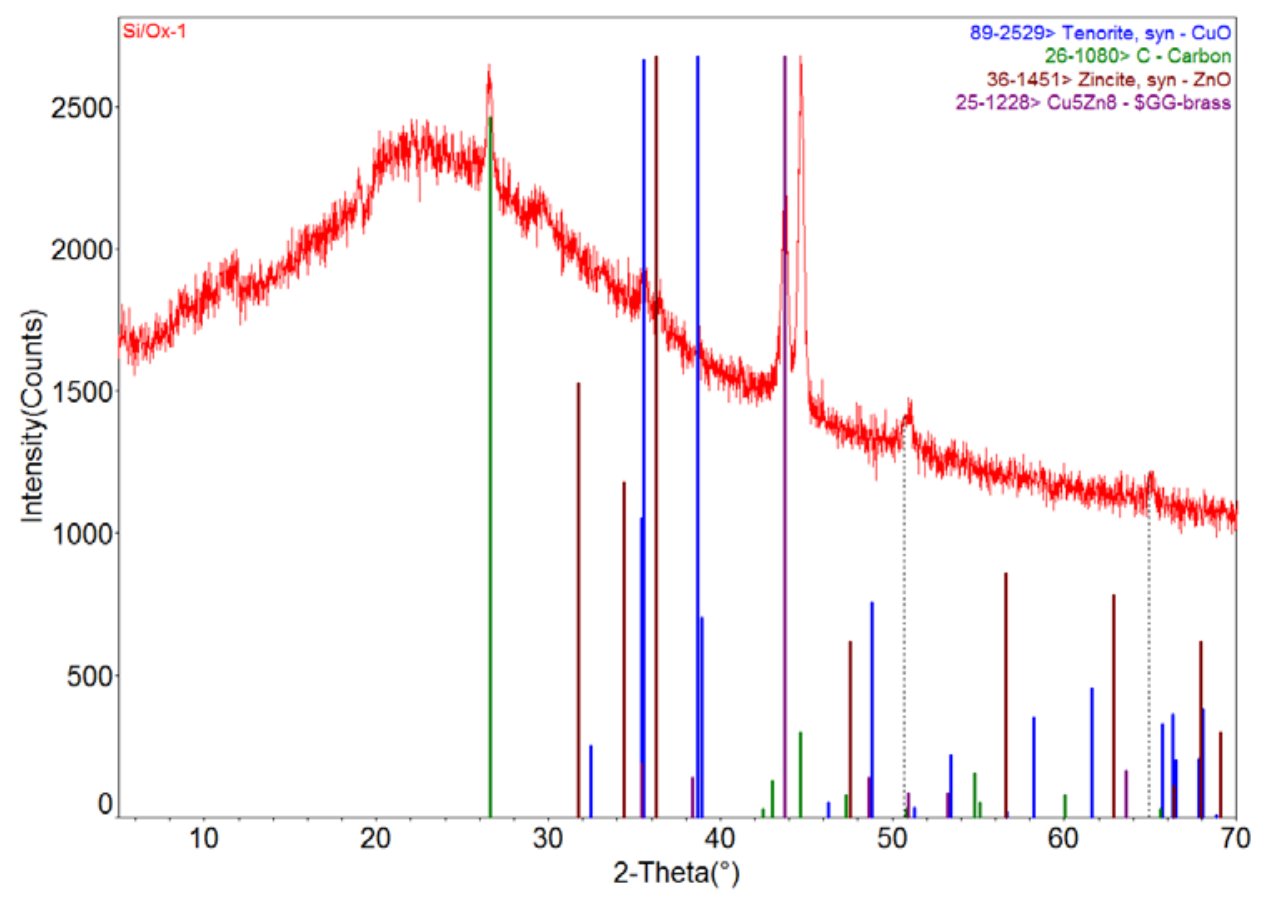

Figure 3. X-ray diffraction pattern of a coating on a plug in the exhaust line deposited during the tenhour period in which siloxane was injected into the engine. The very broad peak centered at around $23^{\circ}$ indicates the coating is largely amorphous or glassy. 


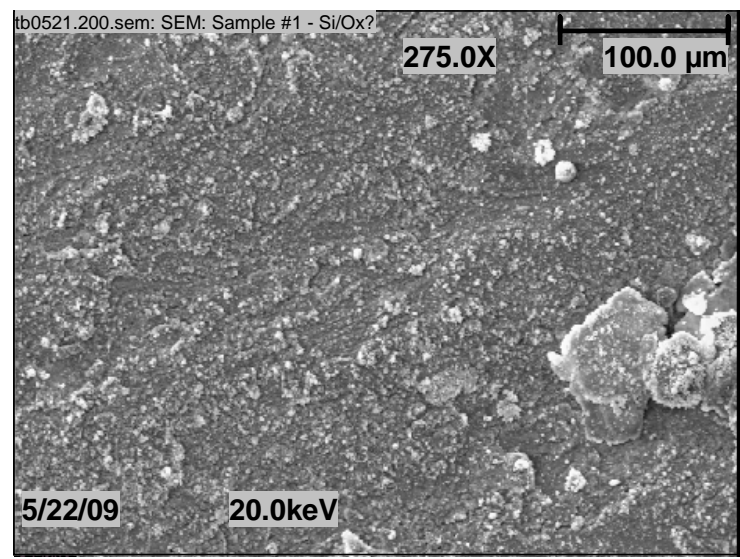

(a)

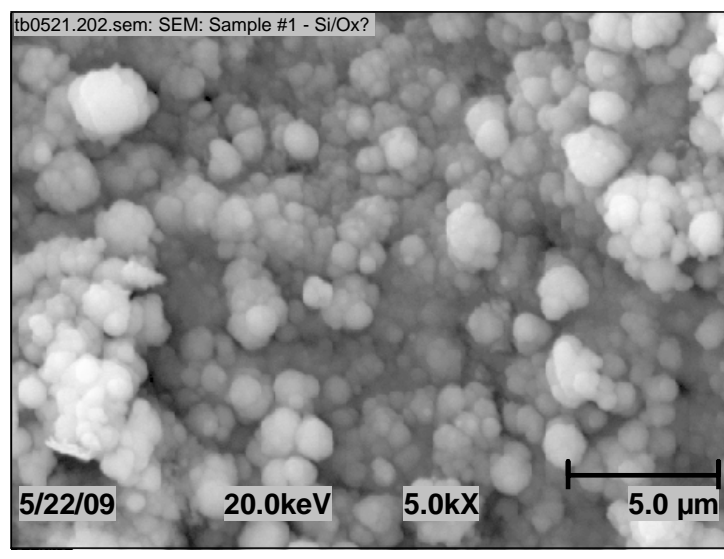

(b)

Figure 4. Secondary electron scattering image of the silica coating on one of the exhaust plugs showing (a) the continuous macroscopic nature of the coating and (b) the microstructure consisting of agglomerated particles.

To better understand the nature of the coatings and their adhesion, standard scratch tests were performed (Fig. 5). The lack of spallation (or delamination) indicates that the coatings were strongly bonded to the surfaces. The scratch hardness values varied from 4.5 to 54.7GPa.
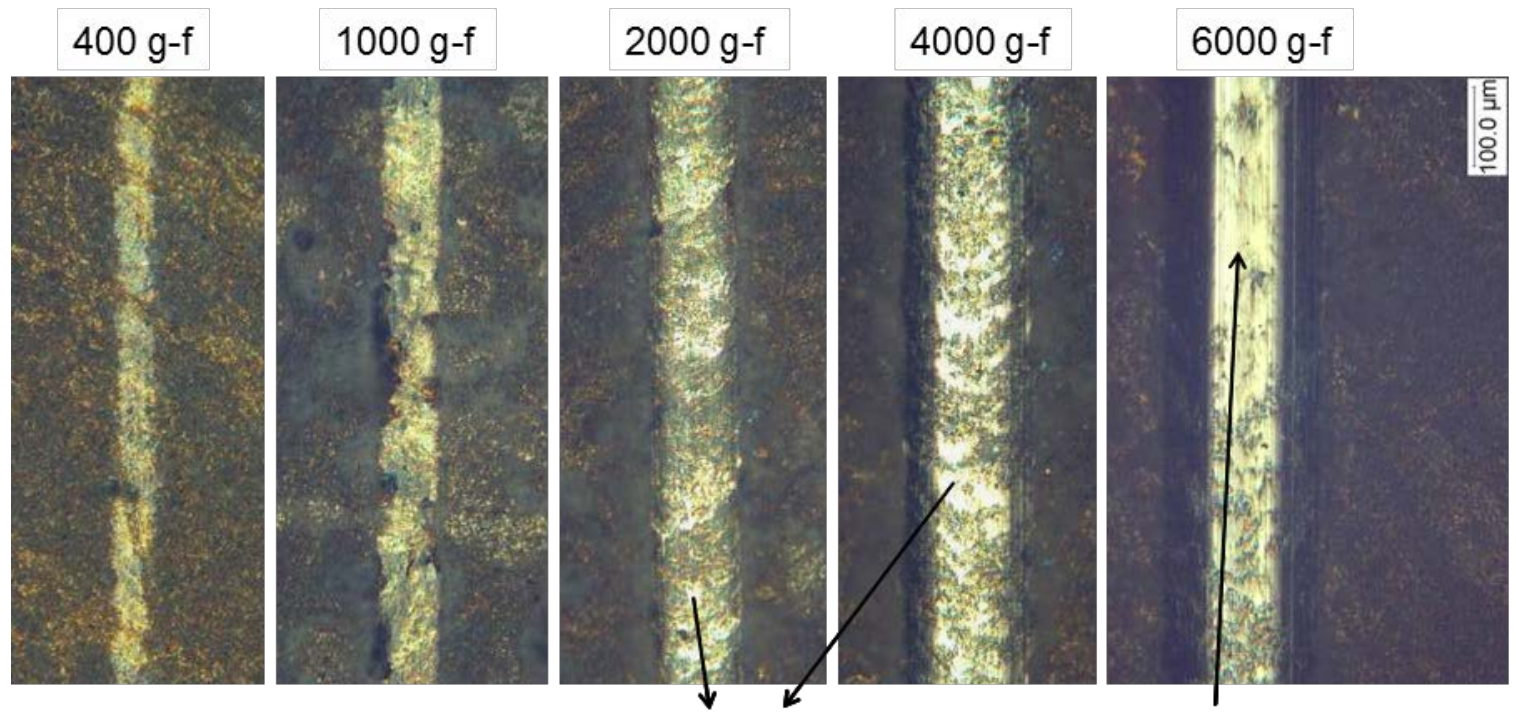

Localized exposure of substrate

Entire film removed

Figure 5. Results of scratch testing at a variety of loads (g-f or grams-force) showing that the coating is adherent as it does not spall or delaminate.

The plugs were replaced and the generator was operated five days a week for seven weeks. The running time was around eight hours per day. During operation, the siloxane was injected into the fuel line initially at a rate of $39 \mathrm{ppm}$ but later increased to $130 \mathrm{ppm}$ to promote silica formation. After 150 hours of operation the engine stopped and the heads were removed. Photographs showing the inside surface of the heads for cylinders 1 and 2 are shown in Figs. 6 and 7, respectively. The higher exhaust temperature for cylinder 1 corresponds to a leaner burning condition and this is also evidenced by the 
lack of hydrocarbon deposits on the head surfaces. For both cylinders, silica buildup was visible on the exhaust gas valve, spark plug, and the exhaust manifold. Buildup was more evident for cylinder 2 and may be related to increased condensation associated with the lower exhaust temperature.

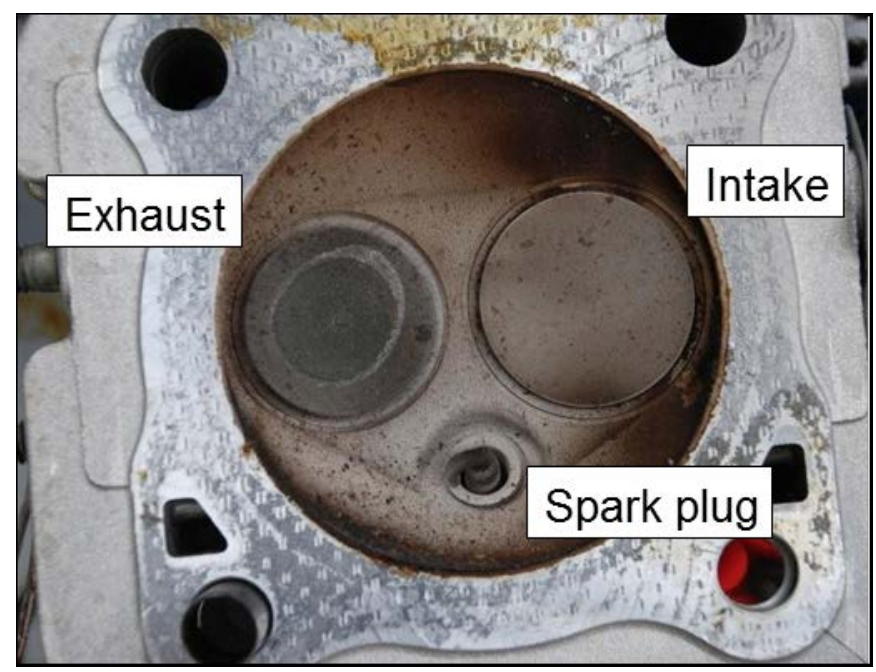

Figure 6. Head from cylinder 1 showing some silica buildup on the exhaust valve and spark plug.

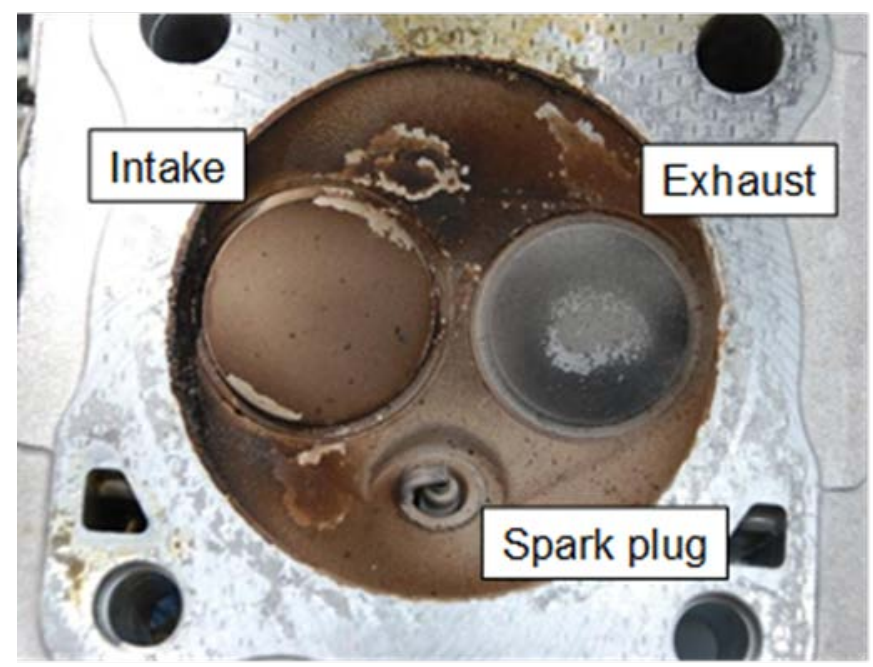

Figure 7. Head from cylinder 2 showing silica buildup on the exhaust valve and spark plug.

The valves and exhaust manifold were removed and were analyzed for silica buildup and phase structure. Scanning electron microscopy (SEM) micrographs of the exhaust valve surface from cylinders 1 and 2 are shown in Fig. 8. For cylinder 1, the silica deposition did not uniformly cover the valve surface, but was deposited preferentially towards the outer radius: the morphology of the silica buildup is dominated by agglomerates with minor regions of glassy-type structure. In contrast, the silica buildup for cylinder 2 (right) is much more glassy in appearance. Auger analysis indicated that the level of calcium (Ca) varied according to position. However, Ca was consistently found to be five times higher in the glassy phases than in the agglomerated zones. Ca is believed to come from the detergents used in the engine lubricant. As the lubricant is oxidized in the combustion chamber, $\mathrm{Ca}$ is incorporated into the silica deposit. 


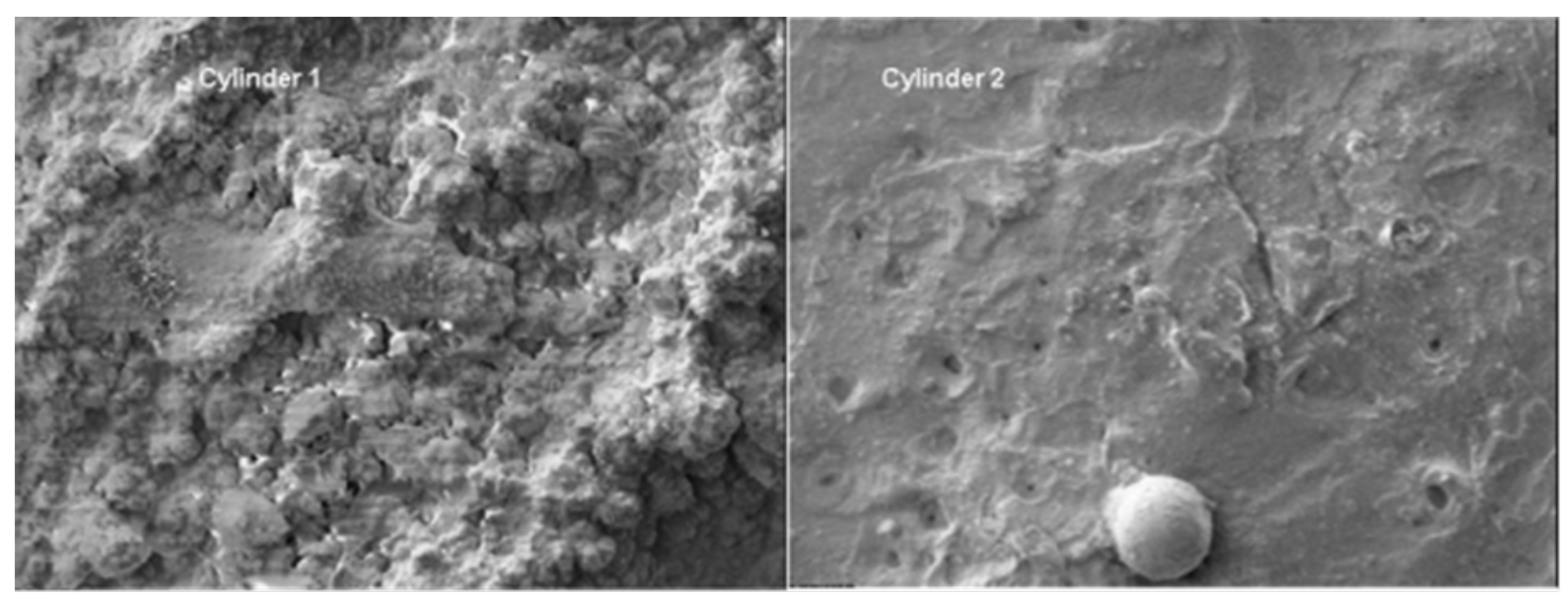

Figure 8. Morphology of silica buildup on exhaust valves showing the difference between cylinders 1 and 2.

In the next experiment, the engine was operated at a lower load ( $3 \mathrm{~kW})$ for approximately 100 hours with siloxane being introduced into the fuel line with a resultant concentration of $1050 \mathrm{ppmv}$ inlet concentration. Rapid buildup of silica was observed on the spark plug electrodes, which subsequently prevented consistent ignition of the fuel and necessitated frequent replacement of the spark plugs.

\subsection{TASK 2 - DEVELOP AND EVALUATE POTENTIAL SILOXANE MITIGATION STRATEGIES}

Two different approaches were examined for mitigating the effects of siloxanes on engine deposits during the combustion of landfill gas. The first approach focused on a novel gas separation method to remove siloxanes and other heavy contaminants from the gas; the second focused on addition of material to the combustion chamber to encourage the formation of soft silicate deposits that would not result in damage to the engine components and could subsequently be removed at maintenance intervals.

\subsubsection{SEPARATION OF SILOXANE FROM LANDFILL GAS VIA JET SEPARATION}

In this task new approaches to removing siloxanes from landfill gases are being evaluated. One promising method is to separate gas molecules according to their molecular weight (MW) and momentum. Siloxanes, $\mathrm{CO}_{2}$, and other contaminants have significantly higher molecular weights than methane, which can allow for efficient separation using centrifugal or jet separation techniques. Although centrifuge-based methods have excellent separation efficiencies for gas molecules, their operating costs are prohibitive for all but the largest facilities. Jet separators, which have been used extensively in mass spectroscopy (Ryhage, 1964) to enrich heavy analyte molecules from the carrier gas (usually $\mathrm{He}$ or $\mathrm{H}_{2}$ ), separate molecules based on mass and momentum. Because of their simple design, a scaled-up jet separation system may be relatively inexpensive to fabricate and operate. Both a modeling and experimental approach were examined to scale up jet separation to a size that would be suitable for separating siloxanes from landfill gas.

A bench-scale study was performed to examine the feasibility of scaled-up jet separation to separate heavier siloxane gas molecules from a representative carrier gas composition consisting of $\mathrm{N}_{2} \cdot \mathrm{N}_{2}$ was used to avoid laboratory safety concerns related to using a flammable mixture during development. Although the molecular weight (MW) of $\mathrm{N}_{2}$ (28) is higher than that of methane (16), it was felt that the 
difference between the MW of $\mathrm{N}_{2}$ and siloxanes ( 150-200) was sufficient for a proof-of-principle, and any concept that worked with $\mathrm{N}_{2}$ would most likely work better with methane, due to its lower MW. The siloxane compound used in the investigation was hexamethyldisiloxane (HMDS), which has a MW of 162.

In the first experiment, two flow rates of contaminated gas $(15 \mathrm{ml} / \mathrm{min}$ and $40 \mathrm{ml} / \mathrm{min})$ were examined, with the same concentration of siloxane in the matrix being separated. A canister sample of gas was collected downstream of the separation nozzle ("dirty" side) and on the diverted side ("clean” side.) The collected samples were analyzed by GC-MS afterwards, and the corresponding GC peaks of siloxane are shown in Fig. 9 for the two flow rates. The results show that jet separation was effective at partitioning the siloxane compound from the carrier gas and the degree of separation is dependent on the flow rate. When comparing the peak area counts, the higher velocity $(40 \mathrm{ml} / \mathrm{min})$ condition provided a separation efficiency approaching $40 \%$, compared to $20 \%$ for the low speed $(15 \mathrm{ml} / \mathrm{min})$ condition.

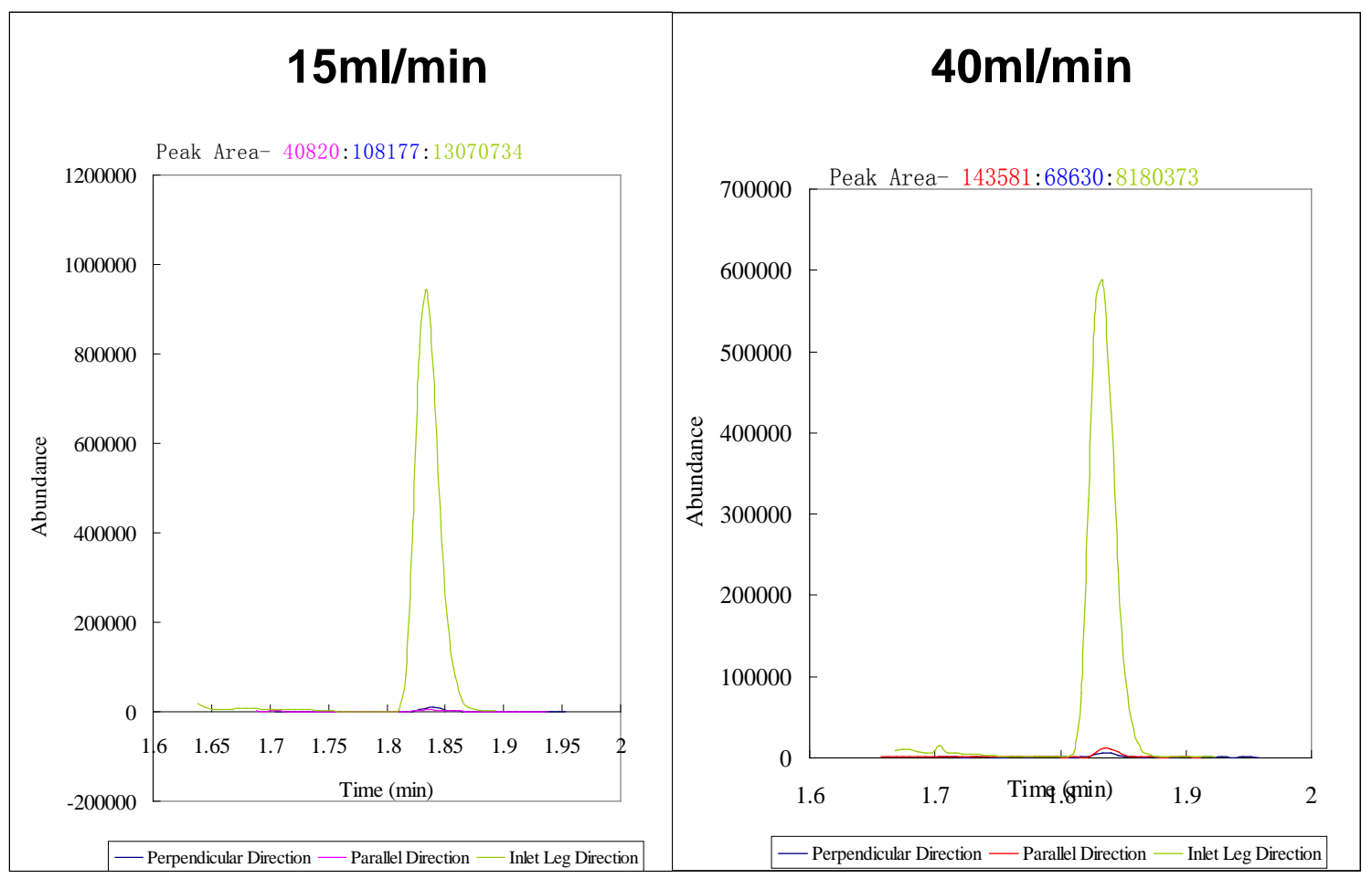

Figure 9. GC/MS analysis showing siloxane separation (peak area counts in parallel direction) for gas flowing at $15 \mathrm{ml} / \mathrm{min}$ and $40 \mathrm{ml} / \mathrm{min}$

Scale up experiments on the jet separator from the milliliter scale to the liter scale were performed. A number of geometries and bore sizes were evaluated. $75 \%$ removal of a surrogate siloxane (e.g. octane, MW=114) from air was achieved at a gap spacing of 0.069 in as shown in Figure 10. This spacing provided the best balance of clean flow and surrogate compound removal.

A Computer Aided Design (CAD) design and flow simulation of the jet separator was also completed, shown in Figure 11. The flows and pressures were input into the CAD program's flow simulation module. The flow simulation program was unable to reproduce the flows and pressures measured experimentally. This confirmed that the flow properties of the separator are unique; the abrupt transitions result in turbulence effects that are not modeled by simple flow simulation models. 
Subsequently modeling was transitioned to a computational fluid dynamics package, MFiX, which stands for Multiphase Flow with Interphase eXchanges. The geometry of a single separator was put into MFiX and the code was run with a simple single phase flow case. Unfortunately, the sharp transitions at the receiving nozzle resulted in mathematical instabilities that were unable to be resolved within the timeframe of the project. In the mass spectrometry application of jet separators, the flow of the mixed gas exits a wide bore capillary, (0.53mm I.D.) and the higher molecular weight components are received by a narrow bore capillary $(0.25 \mathrm{~mm}$ I.D.) The unique properties of capillary flow at high vacuum may be responsible for the high efficiency observed in this application vs. the larger diameters of the scaled-up apparatus. Additional Computational Fluid Dynamics (CFD) modeling may help determine the differences.

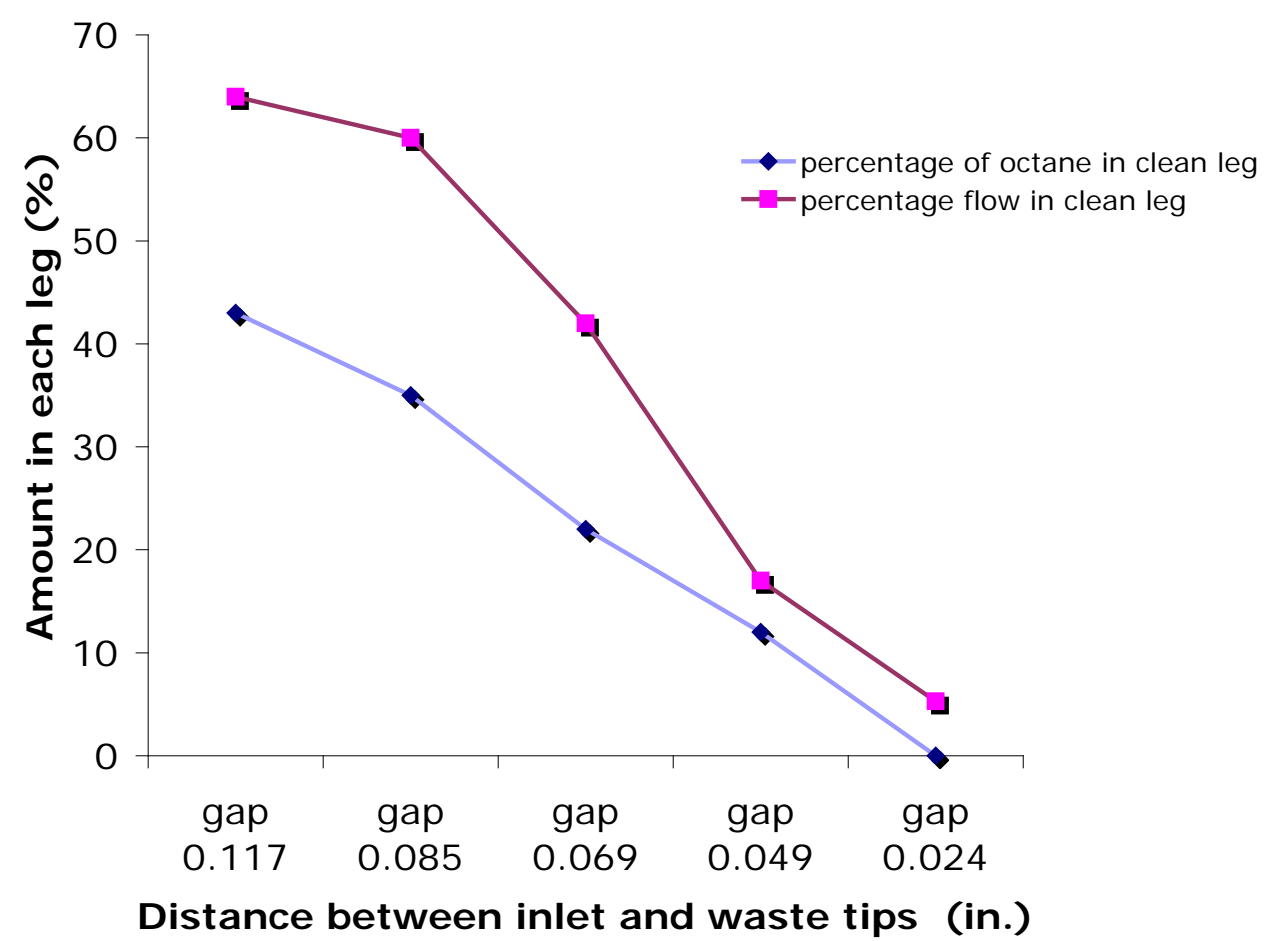

Figure 10. Clean up experiments show that a gap of 0.069 in results in an even distribution of flow, but removal of $75 \%$ of the contaminant.
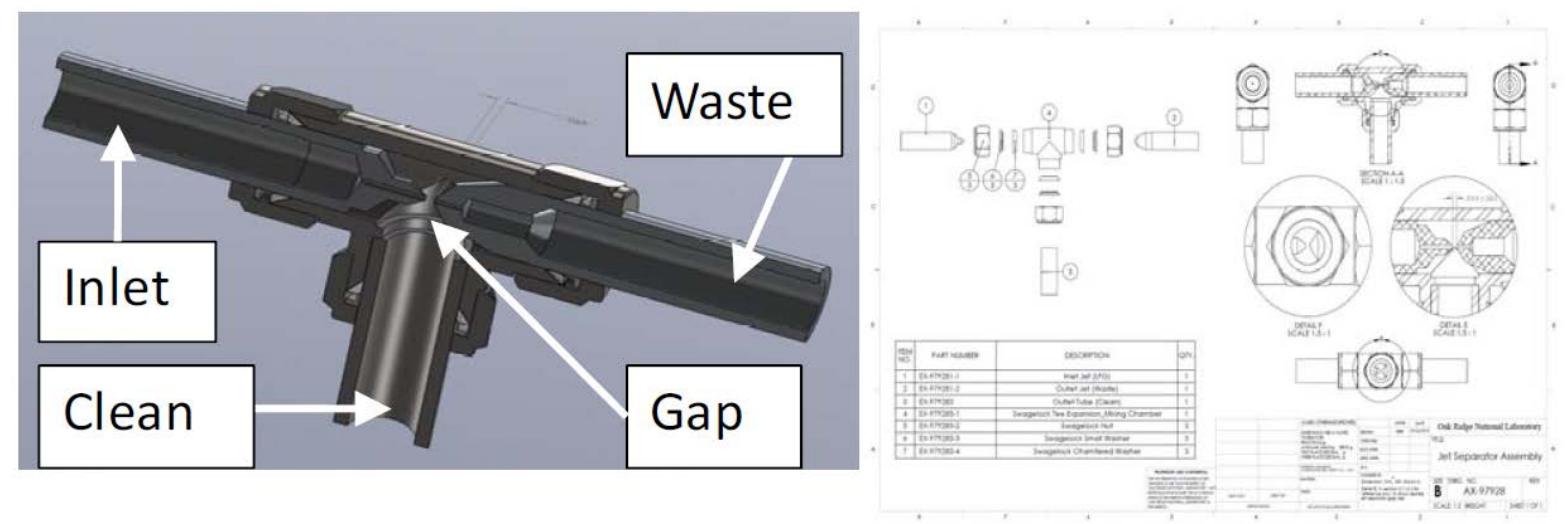

Figure 11. Solid model of the lab scale jet separator done in CAD. Drawings per ASME Y14.5 - 1994 were also generated. 


\subsubsection{Construction and evaluation of a multi-stage manifold.}

A multi-separator manifold was designed and fabricated, shown in Fig. 12. This design allowed variable flow inputs and clean up effectiveness experiments to be conducted. A major difference in this design was the use of high flow vacuum pumps instead of the high vacuum oil-type pumps used in the single separator experiments. High flow is necessary to make the system viable for use in landfill gas cleanup. It was hoped that the data from the multi-stage experiments would provide insight into the feasibility of design for use with actual landfill gas cleanup. The experimental matrix included one, two, and three stage experiments with an emphasis on maximizing the flow rate of cleaned gas. The theoretical maximum of the flow rate through this manifold was thought to be sufficient to fuel the existing small natural gas generator used in the silica deposit studies described above.

\section{Individual jet separators}

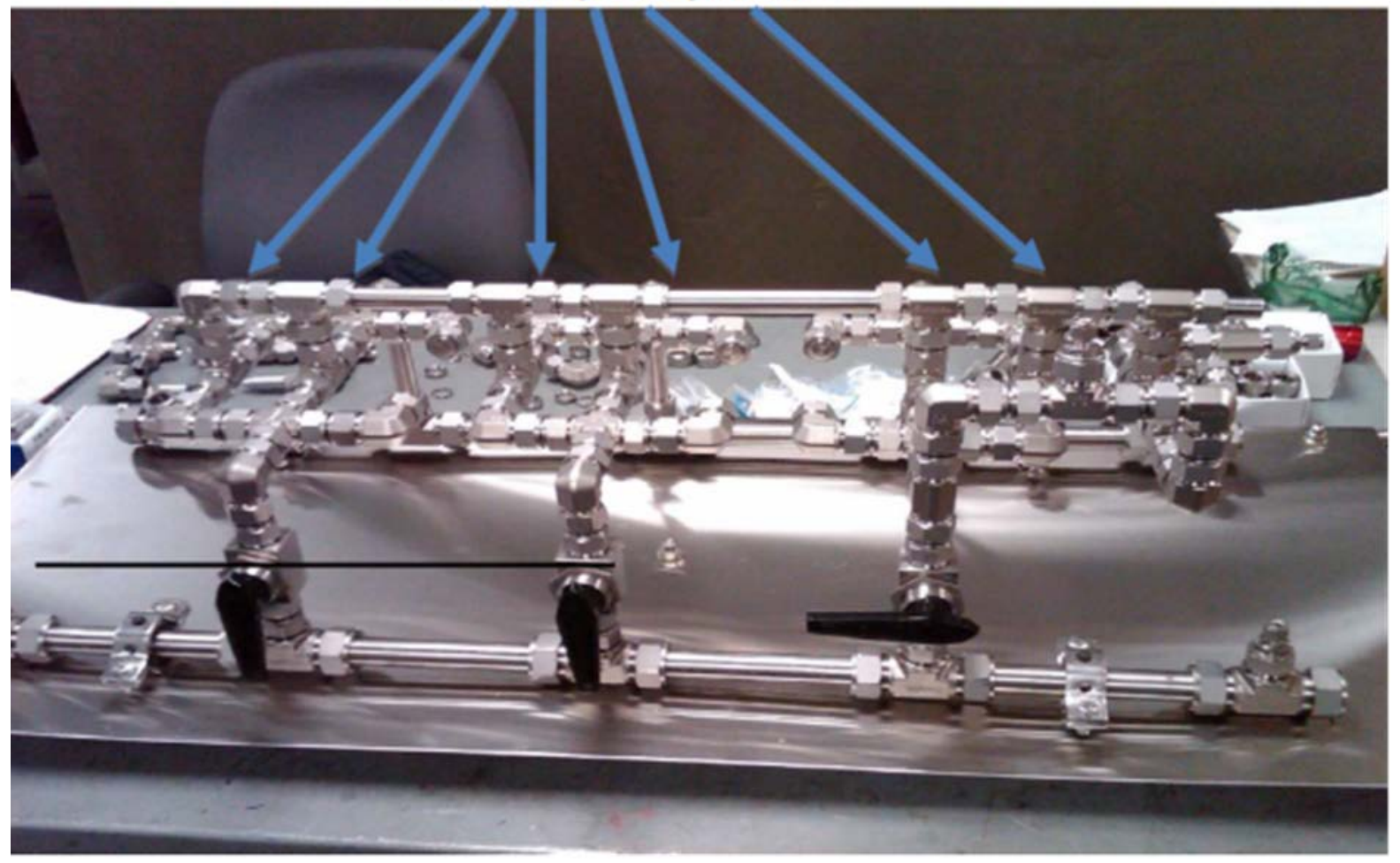

Figure 12. A Jet separator manifold was built to carry out parametric separation effectiveness experiments.

An important design feature of the manifold was incorporation of the ability to change nozzle spacings. A series of tests were carried out at different nozzle spacings to determine separation efficiency in both single stage and two stage configurations. The biggest difference between the multistage system (Fig. 12) and the single stage system shown in Figure 11 was the replacement of the high vacuum rotary vane pumps (e.g. Edwards E2M series) with high flow scroll-type vacuum pumps (Varian Tri-scroll 300.)

Initially, there was some difficulty in obtaining reproducible starting concentrations and thus calculating siloxane removal efficiency. Although the mass spectrometer showed excellent temporal response to the siloxane, it experienced a vacuum pump failure and had to be replaced. A low cost industrial hygiene monitor for silicon-containing gases was substituted for the mass spectrometer. This 
sensor, the RKI Instruments model GD-S77DG, is designed for use with tetraethoxysilane, a common byproduct of silicon wafer manufacturing. The sensor was calibrated with HMDS in air, and, although it had a turndown ratio of $\sim 10$, was sufficient to enable the calculation of contaminant removal by the system.

A series of experiments with single stage and two stage configurations were evaluated. Experiments showed that single stage cleaning only reduced siloxane concentration by $20 \%$ in the best cases, as shown in Figure 13. The addition of a second stage in series resulted in up to $50 \%$ removal of siloxane (Fig. 14.)

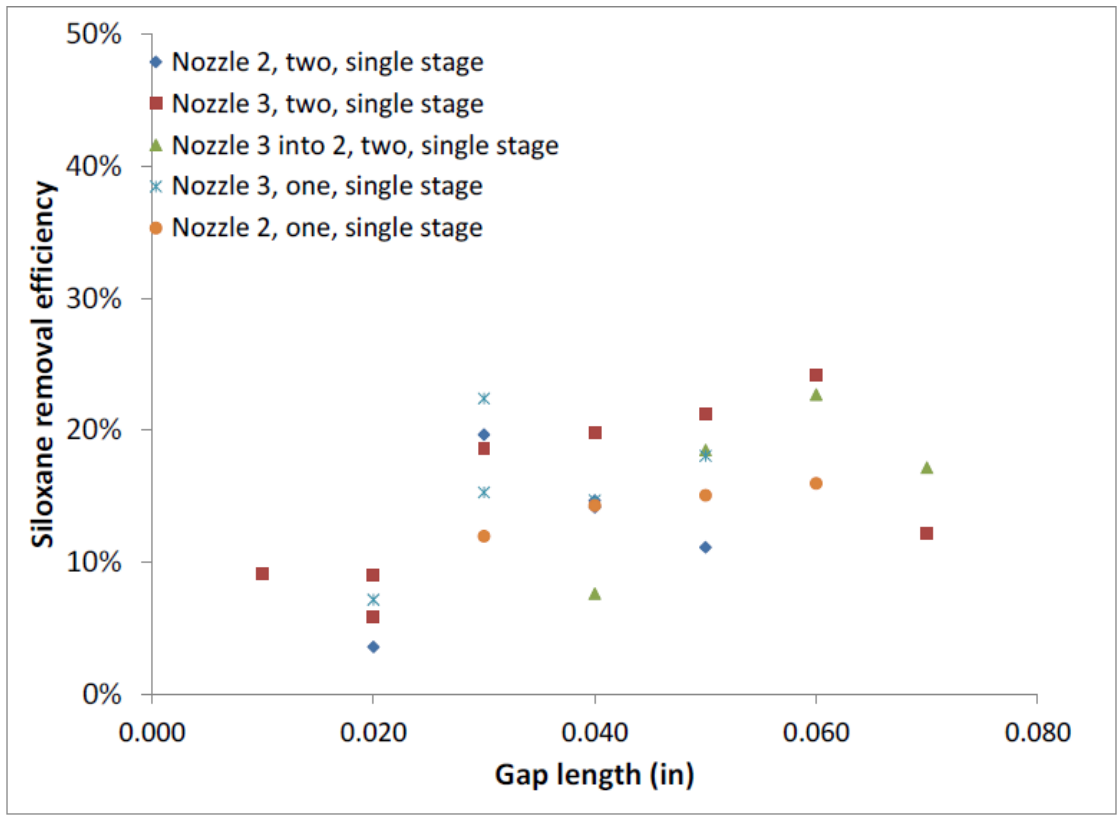

Figure 13. Siloxane removal efficiency for single stage separation, as a function of gap length between the nozzle and receiver.

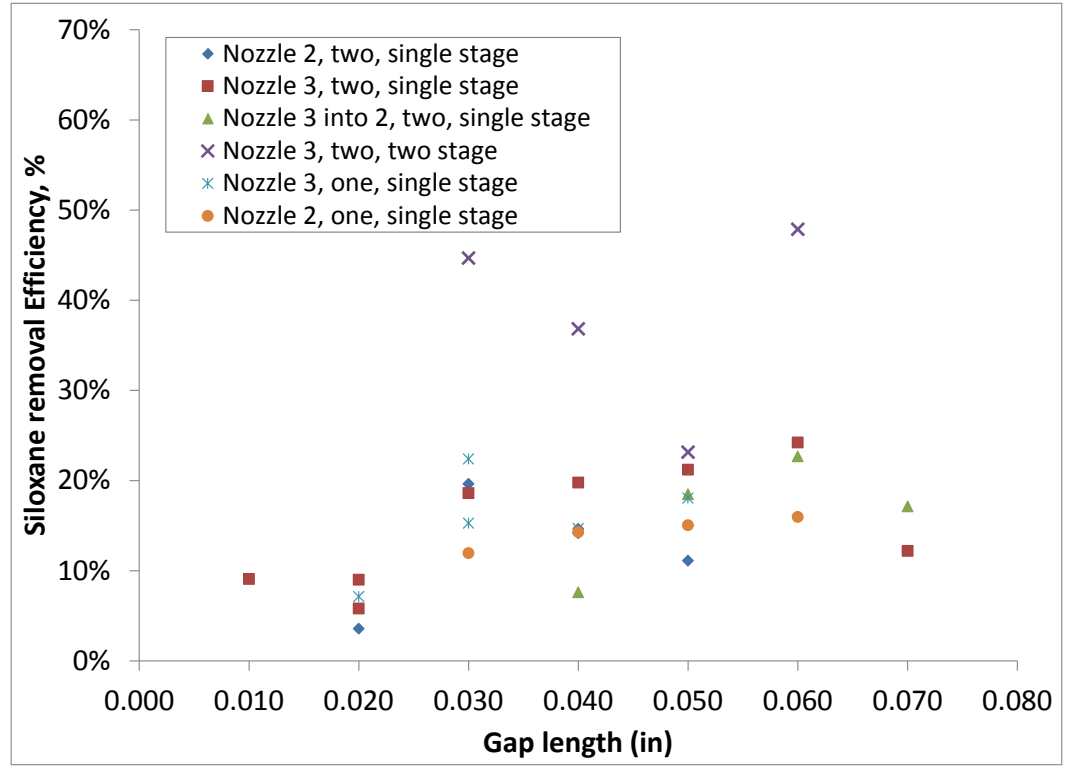

Figure 14. Siloxane removal efficiency for single stage and two stage separation, as a function of gap length between the nozzle and receiver. 
Another way to examine the data was to look at the pressure in the system. A lower pressure requires more pumping work. Figure 15 shows that the 50\% removal efficiency for two stages was achieved with a pressure on the clean side of $\sim 18$ torr, which corresponded to a flow rate of $2.4 \mathrm{lpm}$, out of a total of $6.5 \mathrm{lpm}$.

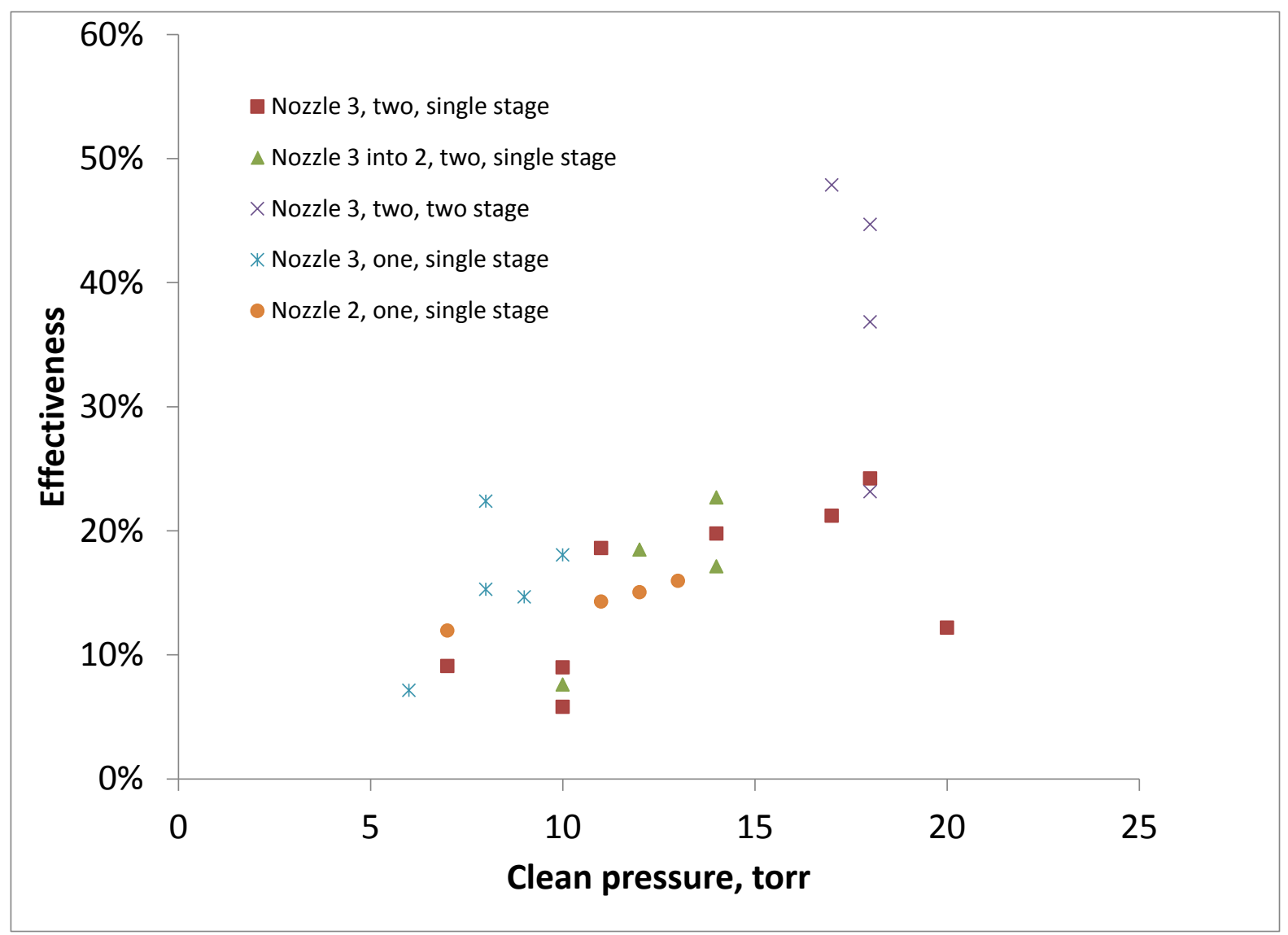

Figure 15. Siloxane removal efficiency as a function of pressure on the "clean" leg of the flow.

The jet separator approach, while promising for the multi-stage case, was ultimately not pursued due to the large difference between the electrical energy required for the vacuum pumps and the energy that could be generated from the recovered methane. About 2/3 more energy in the form of electricity was required to separate the siloxane than could be recovered from the cleaned methane. Further study of the jet separator approach would benefit from more sophisticated modeling to determine how to scale up the phenomena observed at very low pressures with capillary flow.

\subsubsection{Mitigation of Silica Formation in the Combustion Chamber}

Concurrently with the jet separator experiments, a second approach to siloxane mitigation was developed. The concept was to introduce a complexing agent to the intake of the engine to inhibit the formation of hard crystalline silica in the engine. Softer particles could cause less or no engine damage. Also, by rendering the deposits water soluble, it might be possible to wash out the deposits during routine maintenance of the engine. 
Engine experiments focused on the injection of magnesium sulfate $\left(\mathrm{MgSO}_{4}\right)$ into the engine's intake system in an effort to preferentially form magnesium silicate, $\mathrm{Mg}_{3} \mathrm{Si}_{4} \mathrm{O}_{10}(\mathrm{OH})_{2}$, a significantly softer phase than, silica. A replacement small natural gas engine was installed and run with both a representative concentration of siloxane, in the form of HMDS, and the $\mathrm{MgSO}_{4}$, the complexing agent. Extensive exposure ( 100 hours) in the small natural gas engine to both siloxanes and the complexing agent was completed. Deposit samples were taken from the spark plug, a metal exhaust plug and the exhaust outlet. Additionally, aerosol samples from the exhaust were taken and particle mass concentration measured. Deposit analysis found that no complexation had taken place (Fig. 16), and that less than $10 \%$ of the material remained in the exhaust as exhaust particles. Importance of the latter result is the implication that significant surface deposition was occurring, both in the intake and the internal engine surfaces. If the deposits exited the exhaust as super-micron particles, it is likely that they were not sampled.
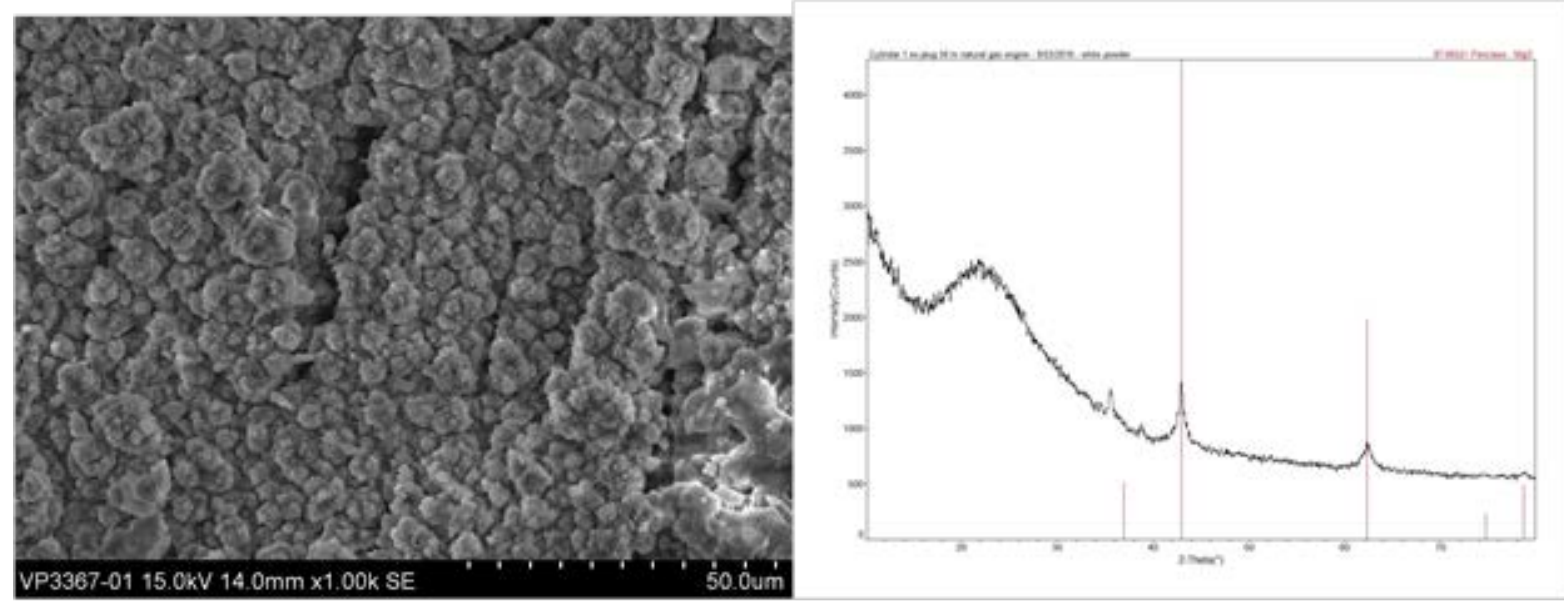

Figure 16. Results of engine deposit mitigation experiments with the $\mathrm{MgSO}_{4}$ complexing agent. The micrograph of engine deposits showed particle sizes of 1- $10 \mathrm{um}$ in the deposit. $X$-ray diffraction results (on the right) show a combination of an oxide and $\mathrm{SiO}_{2}$ in the deposits, with no evidence of complex formation.

In order to better control the combustion of siloxanes and the complexing agent, experiments were also done with a burner. A burner, typically used in an atomic absorption spectrophotometer apparatus, was modified to allow injection of siloxanes and the complexing agent into the flame. Appropriate hydrocarbon/air mixtures plus the siloxanes and additives were used to generate representative combustion environments. The flame was allowed to impinge on metallic surfaces representative of engine cylinder components (Fig. 17.) The deposited material was analyzed to determine whether silica forms from the siloxanes, as occurs in the landfill gas engines, and then the effect of additives to mitigate the silica was evaluated.

In this apparatus, syringe pumps provided siloxane solution and the reactants such as $\mathrm{MgSO}_{4}$ solution to the flame. Aluminum disks were used as the substrates to simulate engine components. The disks were mounted on a water-cooled stage that was held above the flame at any position (Fig. 18). A number of preliminary experiments were performed to establish conditions for formation of silica layers on the aluminum substrates. Significant silica is deposited on the substrates, but fails to form a as hard a layer as found in landfill gas engines. Experiments to find the right conditions for deposition to simulate the deposited layers in engines continued, and Figure 18 shows a coating of powdered silica on the sample. 


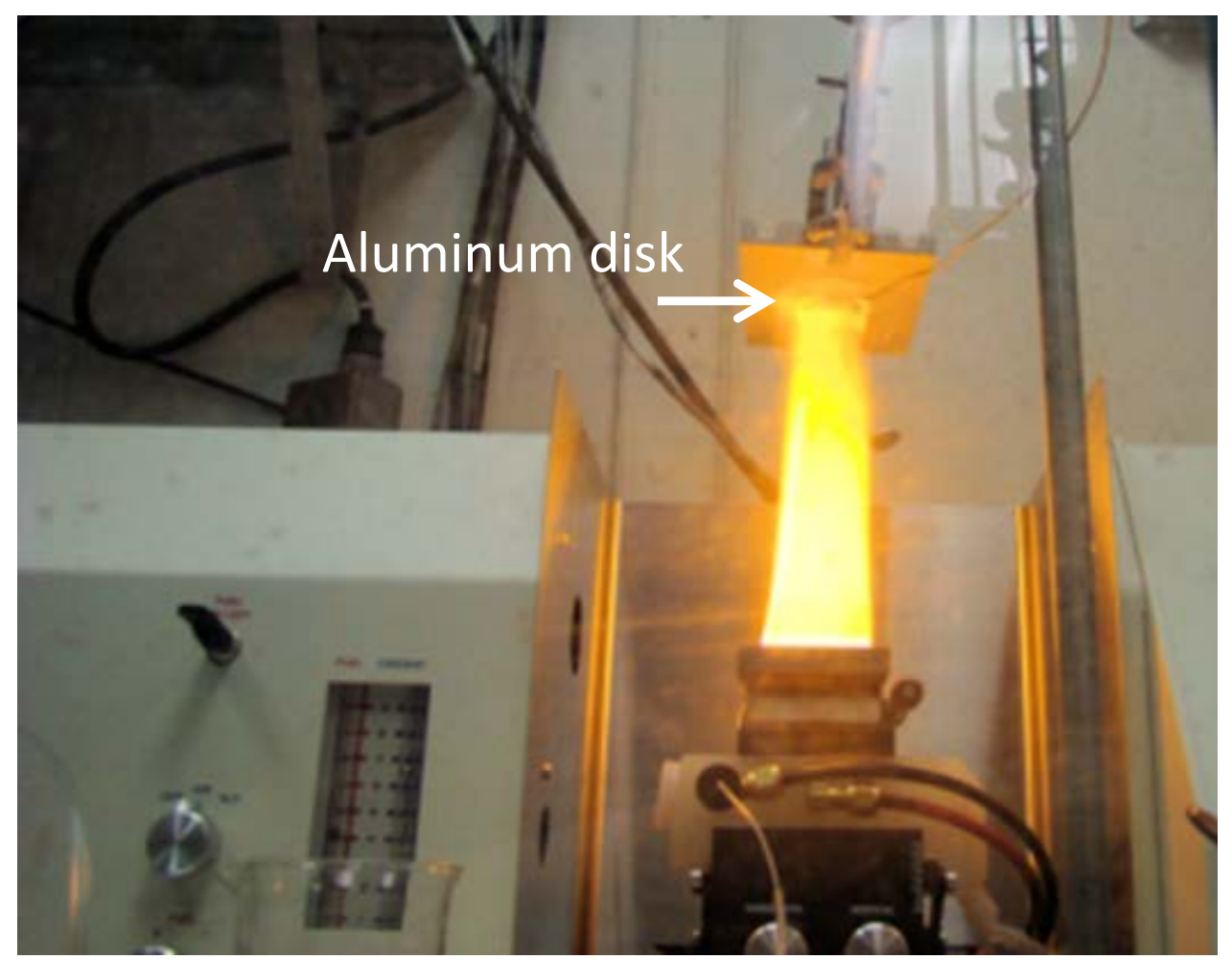

Figure 17. Spectrophotometer flame containing siloxanes impinging on aluminum substrate.

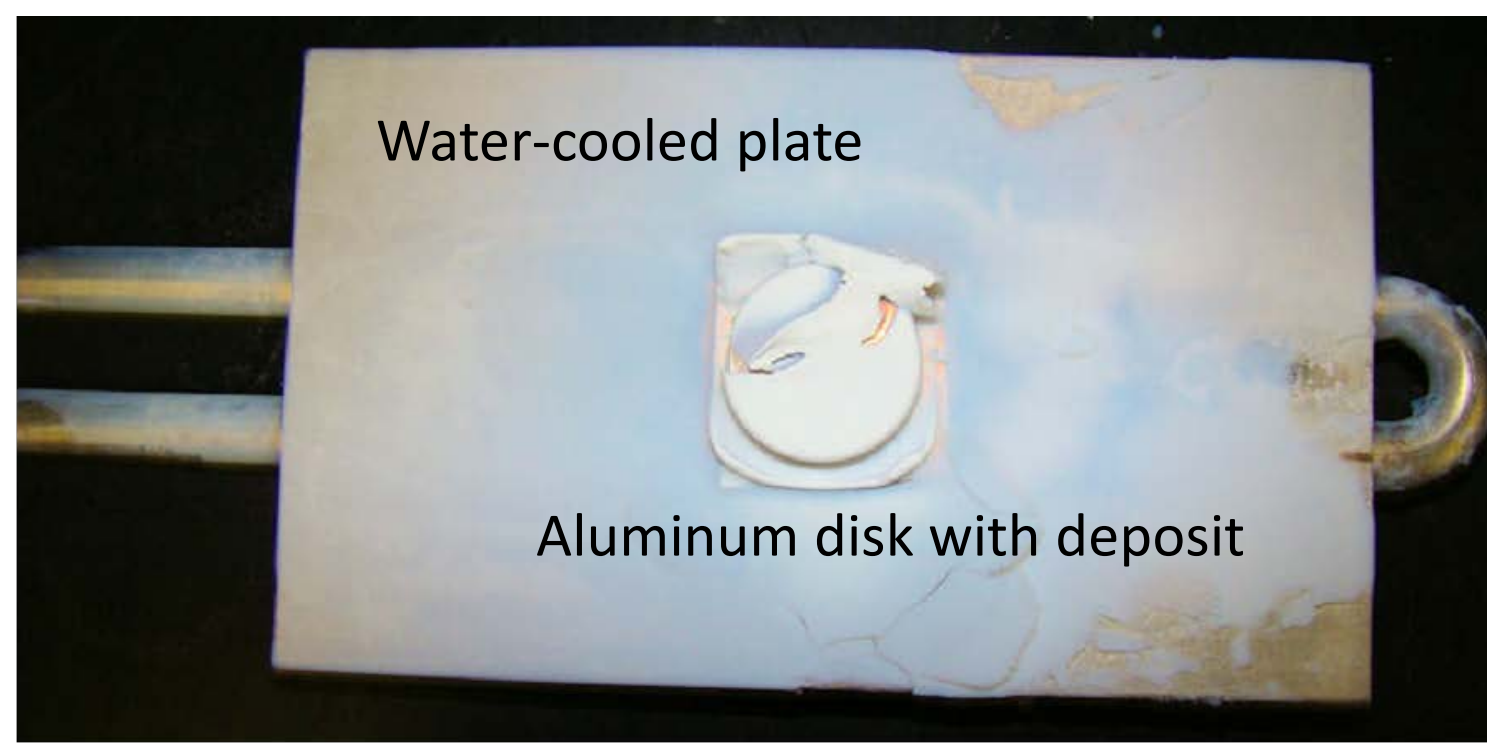

Figure 18. Aluminum substrate disk mounted on cooling plate coated with deposited silica.

In all, 31samples were run under varying conditions. Conductivity from the Al disk specimen was reduced by removing water cooling after run 1 , changing to a steel plate after run 8 , and changing to a smaller steel plate on run 17 . The original aluminum substrates were replaced at run 10 with tool steel and at run 13 with steel alloy 4340 to better simulate piston material.

Flow rates ratios and concentrations of precursors were varied over several runs. HMDS by itself produced poor coatings. Fuel rich coatings had excess carbon instead of reducing oxygen content. 
Using nitrous oxide instead of oxygen as an oxidizer produced higher temperature flames. Coatings using multiple precursors tend to exaggerate the contribution of the secondary element.

The most success was obtained using secondary precursors containing $\mathrm{Na}$, Ca and re-firing the sample at $1000^{\circ} \mathrm{C}$ in argon to fuse the coating to the substrate. Two runs at varying Na concentrations were subsequently heated to form adherent coatings most reminiscent of the coatings formed on landfill gas engine components. Micro-indentation measurements were performed on the coatings that averaged $\sim 4.3$ on the Knoop hardness scale, or a factor of 10 to 100 lower in hardness than the coatings made in the small research engine and shown above in Figure 5. Figure 19 illustrates one of the sample disks after re-firing.

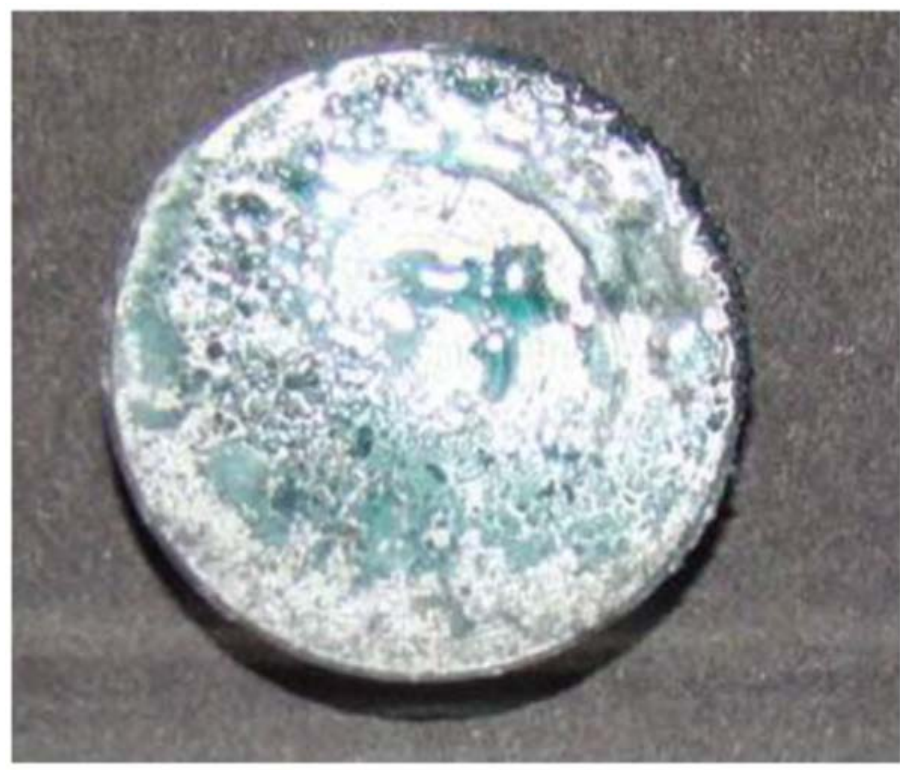

Figure 19. An example of a 4340 steel substrate coated with deposited material with a precursor ratio of Na:Si of $1: 5$ followed by heat treatment at $1000^{\circ} \mathrm{C}$ for $1 \mathrm{~h}$ to fuse the material to the substrate.

A patent was filed in 2011, and awarded in 2014, \#8,631,770 for "Mitigating the Effect of Siloxanes on Internal Combustion Engines Using Landfill Gasses" using this approach. This effort was discontinued early in FY2012 due to the re-direction in the Fuel and Feedstock Flexibility (FFF) Research and Development program.

\subsection{TASK 3 - DEVELOPMENT OF A SILOXANE SENSOR TO OPTIMIZE MITIGATION STRATEGIES}

Real-time detection of siloxanes in landfill gas is challenging due to the low concentration of the siloxanes, typically 1-100 ppm, vs. the other major components such as $\mathrm{CO}_{2}$. A proof-of-principle study to assess the feasibility of microcantilever-based sensing methods was led by researchers within the Department of Chemistry at the University of Tennessee, Knoxville, in collaboration with ORNL.

During Phase 1 of the investigation, microcantilever arrays were tuned to be sensitive to gaseous siloxane compounds. The cantilevers on the array were differentially coated on the active, nanostructured side with different responsive phases, Coatings A-G, and the responses of four siloxane compounds pentamethyl disiloxane (PMDS), hexamethyl disiloxane (HMDS), octamethyl trisiloxane (OMTS), and decamethyly cyclopentasiloxane (DMCPS), exhibited signature selectivity as shown in Fig. 20 (when using inert helium as the carrier gas). 


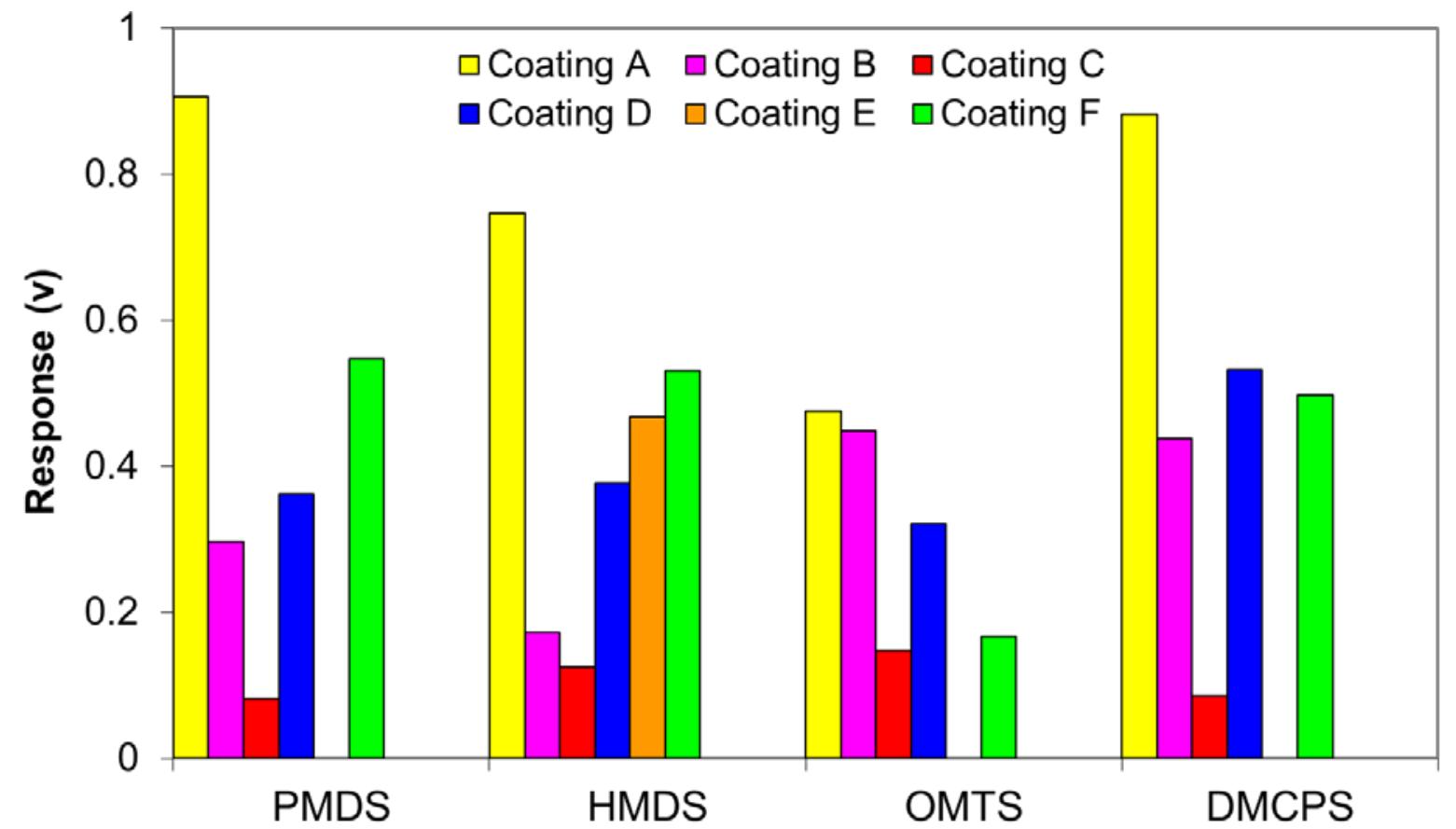

Figure 20. Selectivity of the microcantilever array to various types of siloxane compounds at $1 \mathrm{ppm}$ in helium.

Follow-on efforts focused on replacing the helium with a more realistic gas composition. Interferences were noted with other gas constituents, and coating materials less susceptible to interference from other gas components such as $\mathrm{CO}_{2}, \mathrm{CH}_{4}$, and $\mathrm{H}_{2} \mathrm{O}$ were evaluated. In addition the response time of the sensor was evaluated. Much more detail appears in Long et al., 2009.

The sensor team at the University of Tennessee constructed a field-transportable sensor unit intended for use at the Iris Glen Landfill. The micro-cantilever based sensor for contaminants was made field portable into a small plastic case (Fig. 21). The field transportable sensor unit was first demonstrated at the ORNL-FEERC (Fig. 22.) The sample was withdrawn from the intake manifold of the small natural gas engine. The gas feeding the intake manifold had been augmented with a known amount of siloxane. 


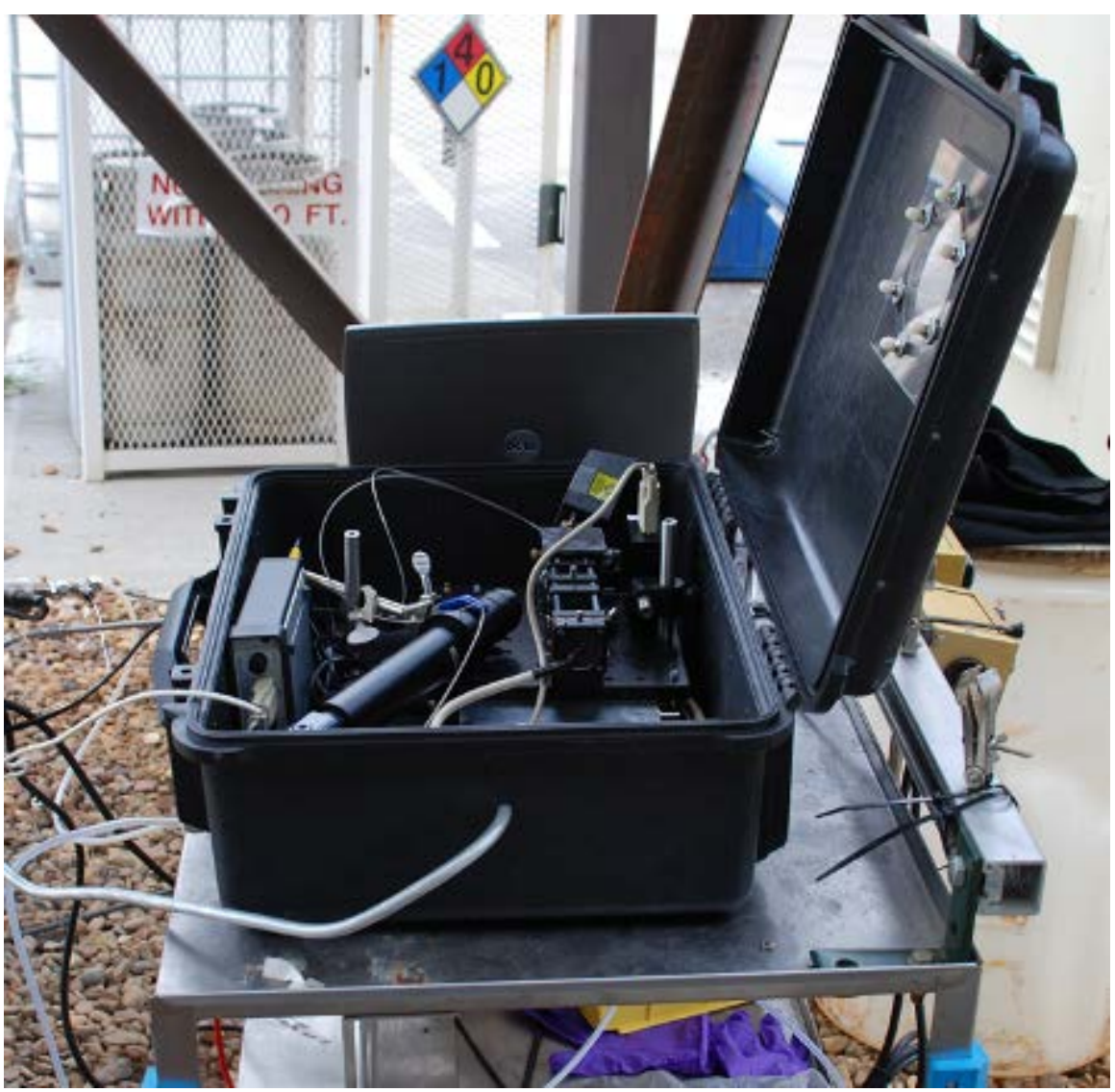

Figure 21. Field-transportable sensor.

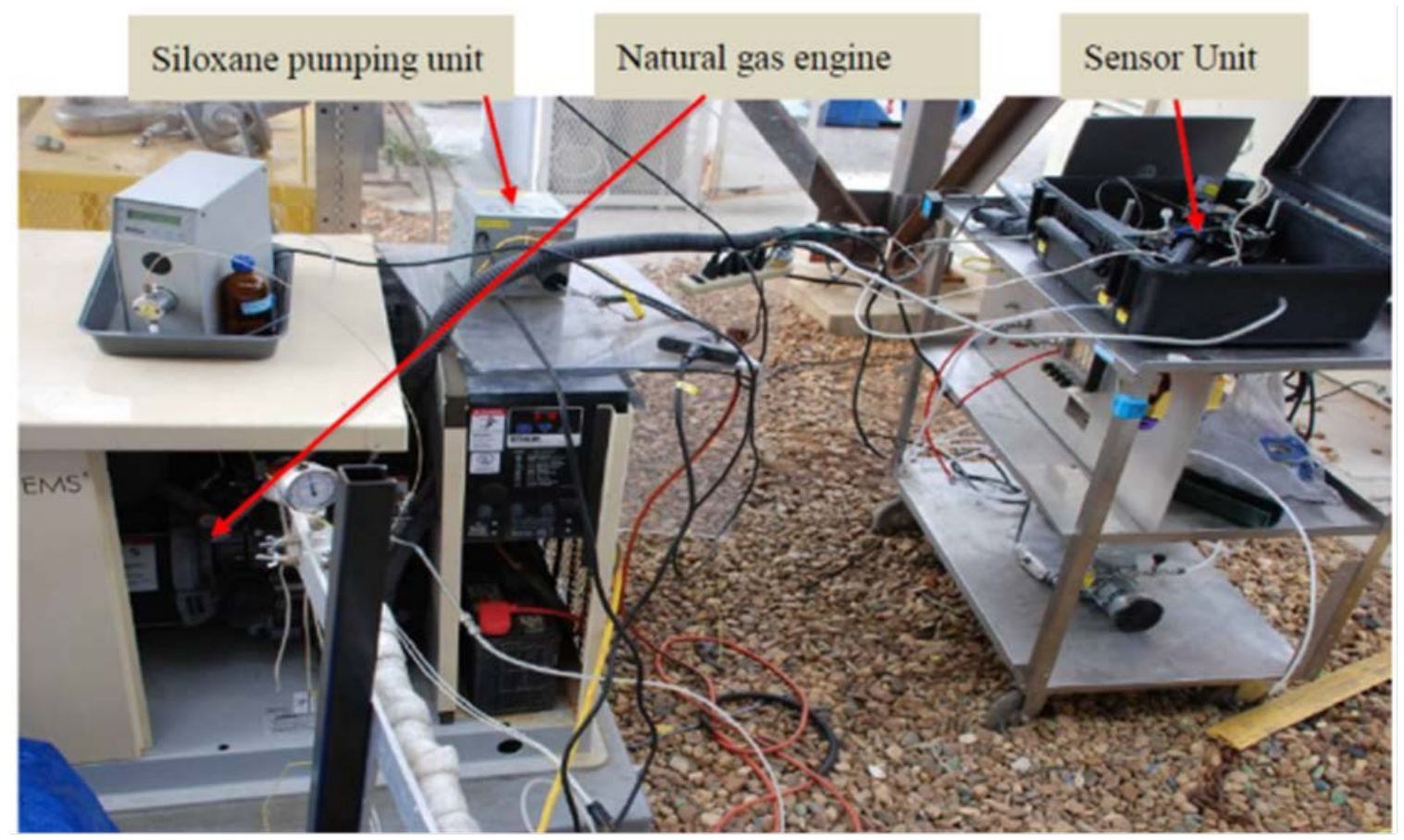

Figure 22. Field transportable siloxane sensor being tested on a natural gas engine generating siloxane containing exhaust. 
Testing was conducted with favorable results, summarized in Fig. 23. As shown, micro cantilever coatings 4 and 7 had the best response for the DMCPS siloxane, also known as D5.

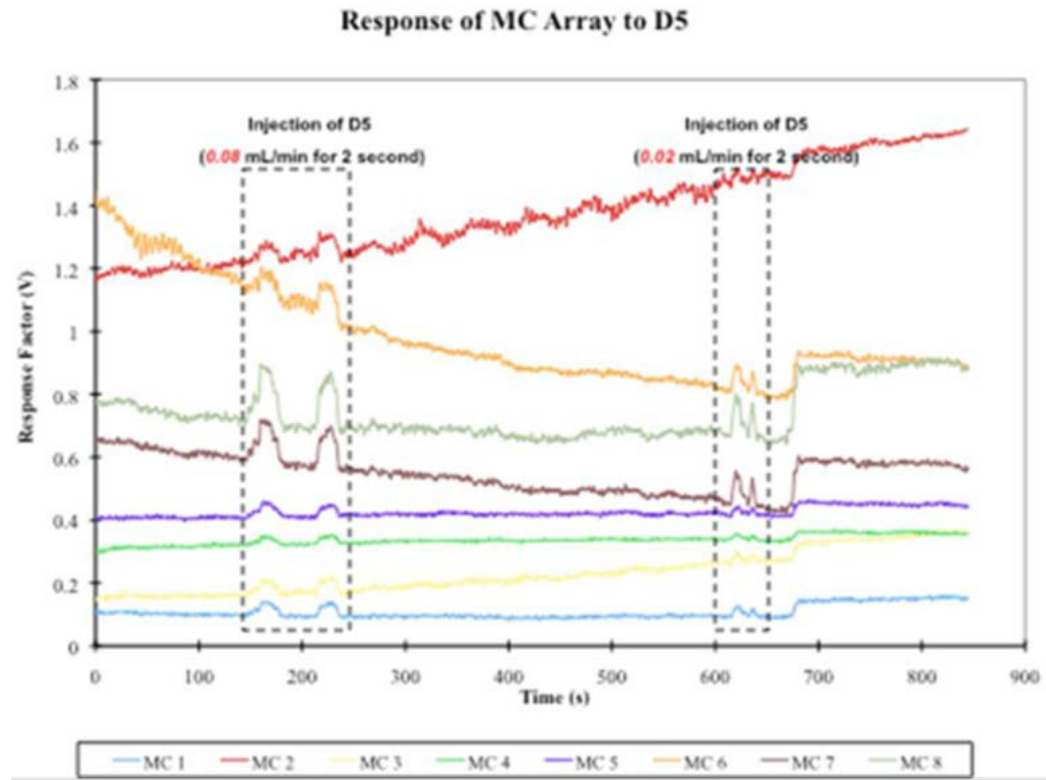

Figure 23. Response of the sensor array to siloxane contaminants in engine intake gas. MC1 - MC8 refer to different coatings on the microcantilevers.

Based on these results, the thermostatically-controlled heated cell, shown in Figure 24, was designed and installed in the sensor unit. Heated cells can control contamination and condensation inside the sample cell. This cell was able to correct the loss of sensitivity when the sensor is exposed to water in the gas and temperatures above $20^{\circ} \mathrm{C}$. The work was completed in FY2012 on the sensor and reported in Long et al., 2009.

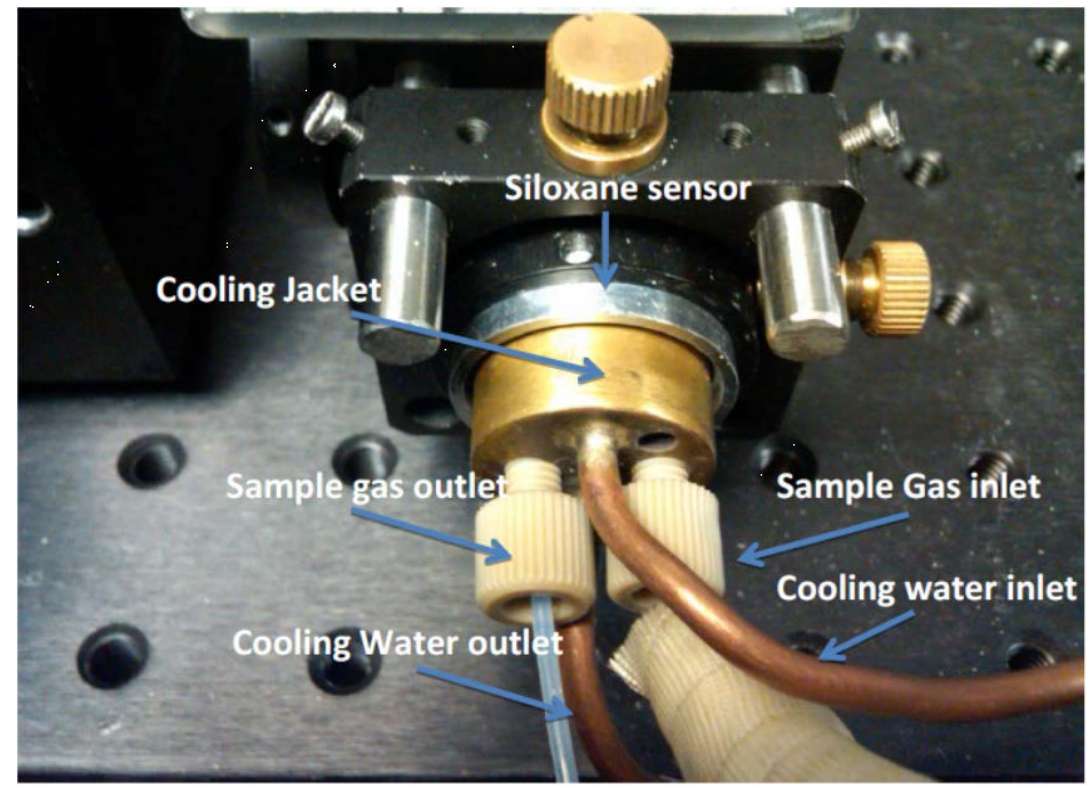

Figure 24. Heated, thermostatically-controlled sensor cell. 


\section{ACCOMPLISHMENTS AND CONCLUSIONS}

The tasks making up this project had several successful outcomes. A new canister sampling and analysis method was developed for siloxane detection in grab samples of landfill gas. A small natural gas engine demonstration showed that it was possible to reproduce silica deposit formation in a combustion chamber by doping the feed gas with siloxane. Finally, a sensitive and selective sensor system for siloxanes in a landfill gas matrix was demonstrated.

While the two mitigation strategies, the jet separator and the complexation additive, were not fully investigated due to the discontinuation of the research program, both strategies showed some promise. The jet separation technology led to the filing of an invention disclosure, while the siloxane mitigation strategy led to the award of a patent in 2014. Additional research on these strategies may yield fieldready systems to solve a challenging problem for landfill gas energy systems.

\subsection{PATENTS}

Invention disclosures

- Invention \#2094 - Gaseous Fuel Purification by Jet Separation, not pursued.

- Invention "Mitigating the Effect of Siloxanes on Internal Combustion Engines Using Landfill Gasses,” Patent \# 8,631,770 awarded January 21, 2014. Theodore M. Besmann

\subsection{PUBLICATIONS AND PRESENTATIONS}

Z. Long, Storey, J.M. E., Lewis, S. and M. J. Sepaniak, ”Landfill Siloxane Gas Sensing Using Differentiating, Responsive Phase Coated Microcantilever Arrays,” Anal. Chem. 2009, 81, 2575-2580

\subsection{COMMERCIALIZATION}

This project demonstrated a sensor technology for detecting siloxanes at the ppm level in landfill gas with a portable unit. While the micro-cantilever array approach to sensing siloxanes in landfill gas was demonstrated, a commercial sensor would need to be miniaturized for use commercially. The packaging and miniaturization step were beyond the scope of this project.

Two siloxane mitigation strategies were examined. The jet separation technology was determined to be too energy intensive for practical application. A patent was issued on the second concept of reducing the formation of hard deposits. This patent is currently available for licensing. The mitigation strategies, while showing promise as being viable approaches, would need further development before commercialization could be considered.

\subsection{RECOMMENDATIONS}

It is recommended that future work focus on the miniaturization and packaging of the micro-cantilever array sensor. The need still remains for a robust and inexpensive, real-time sensor for siloxanes in landfill gas. Such a sensor would enable feedback control of existing and future siloxane cleanup technologies. For instance, for activated carbon bed removal of siloxanes, a real-time sensor would potentially extend the replacement interval of the activated carbon. Once breakthrough of the siloxane was sensed, the bed could be replaced, in contrast to existing practice of replacing the activated carbon at set intervals. 


\section{REFERENCES}

Hayes, H.C., Graening, G. J., Saeed, S., and S. Kao, ”Summary of available analytical methods for the determination of siloxanes in biogas," Proceedings of the 2003 SWANA Landfill Gas Symposium. Solid Waste Association of North America, 2003.

Wheless, E. and J. Pierce, "Siloxanes in Landfill and Digester Gas Update,” Proceedings of the 2004 SWANA Landfill Gas Symposium. Solid Waste Association of North America, 2004.

Wheless, E. and D. Cary, “Siloxanes in Landfill and Digester Gas,” Proceedings of the 2002 SWANA Landfill Gas Symposium. Solid Waste Association of North America, 2002.

Ryhage, R. "Use of a Mass Spectrometer as a Detector and Analyzer for Effluents Emerging from High Temperature Gas Liquid Chromatography Columns,” Analytical Chemistry, v.36, no.4, pp.760764. 1964.

“An Overview of Volatile Methylsiloxane (VMS) Fluids in the Environment,” Dow Corning Environmental Update, revised September 10, 1997. Dow Corning Corp., Midland, MI. 1997.

Schweigkofler, R. and R. Niessner, "Removal of siloxanes in biogases,” J. of Hazardous Materials B, Vol. 83, pp.183-186. 2001.

Long, Z., Storey, J.M. E., Lewis, S. and M. J. Sepaniak, "Landfill Siloxane Gas Sensing Using Differentiating, Responsive Phase Coated Microcantilever Arrays,” Analytical Chemistry, v.81, pp. 2575-2580. 2009. 